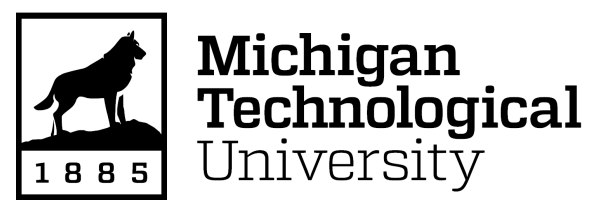

Michigan Technological University Digital Commons @ Michigan Tech

Dissertations, Master's Theses and Master's Reports

2020

\title{
Linking Energy Efficiency and Public Health: A case study of Illinois
}

Azat Turegeldin

Michigan Technological University, aturegel@mtu.edu

Copyright 2020 Azat Turegeldin

\section{Recommended Citation}

Turegeldin, Azat, "Linking Energy Efficiency and Public Health: A case study of Illinois", Open Access Master's Report, Michigan Technological University, 2020.

https://doi.org/10.37099/mtu.dc.etdr/1068

Follow this and additional works at: https://digitalcommons.mtu.edu/etdr

Part of the Energy Policy Commons, Environmental Policy Commons, and the Health Policy Commons 


\title{
LINKING ENERGY EFFICIENCY AND PUBLIC HEALTH:
}

\section{A CASE STUDY OF ILLINOIS}

\author{
By
}

Azat Turegeldin

\author{
A REPORT \\ Submitted in partial fulfillment of the requirements for the degree of \\ MASTER OF SCIENCE \\ In Environmental and Energy Policy \\ MICHIGAN TECHNOLOGICAL UNIVERSITY \\ 2020 \\ (C) 2020 Azat Turegeldin
}


This report has been approved in partial fulfillment of the requirements for the Degree of MASTER OF SCIENCE in Environmental and Energy Policy.

Department of Social Sciences

Report Advisor: Roman V. Sidortsov

Committee Member: $\quad$ Chelsea L. Schelly

Committee Member: Shan Zhou

Department Chair: Hugh Gorman 


\section{Table of Contents}

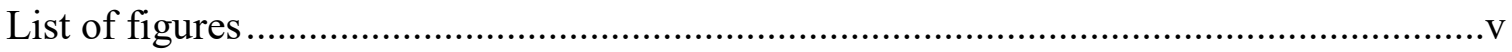

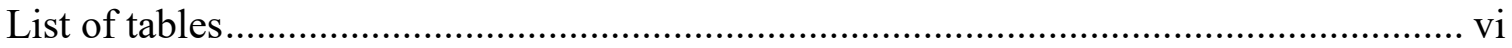

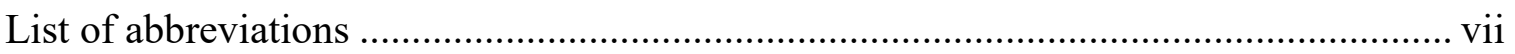

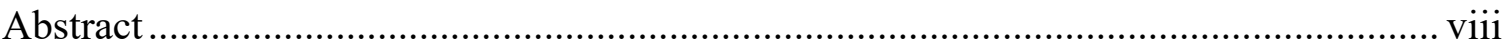

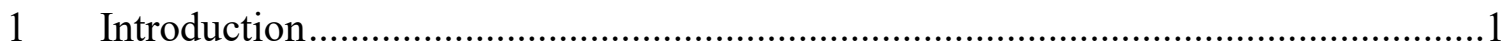

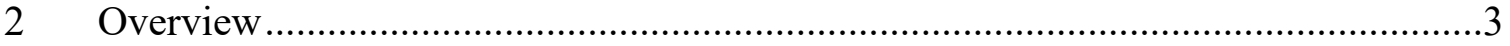

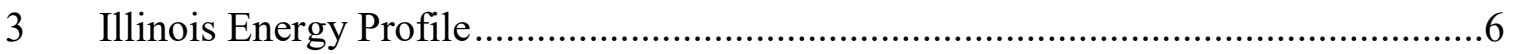

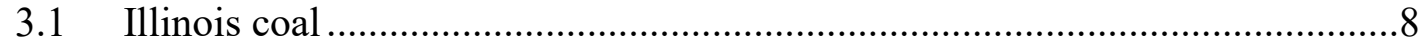

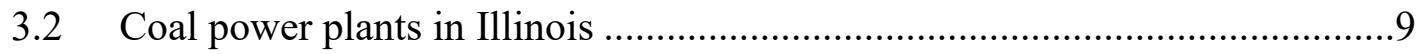

3.3 Illinois Regulatory Framework for Coal Powered Electricity Generation.....10

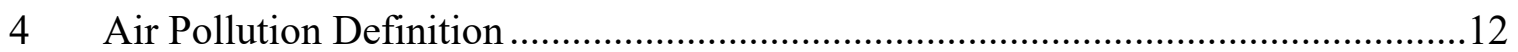

4.1 Types of criteria air pollutants...................................................................13

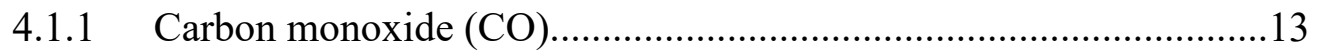

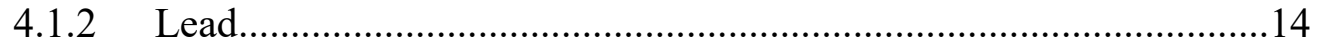

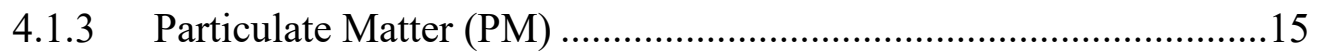

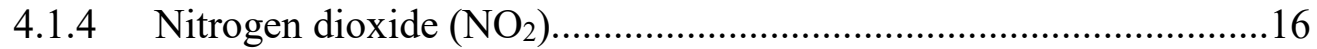

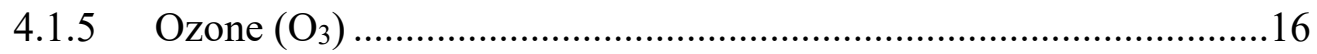

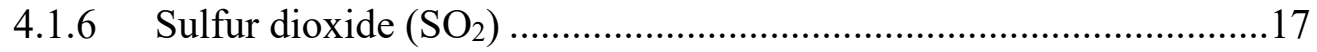

4.2 Clean Air Act (CAA) as a Tool for Protecting Public Health.........................18

$5 \quad$ Health Impacts of Coal ………….....................................................................21

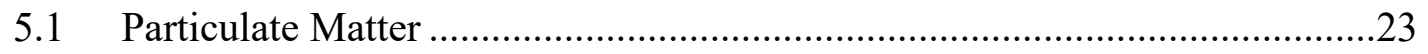

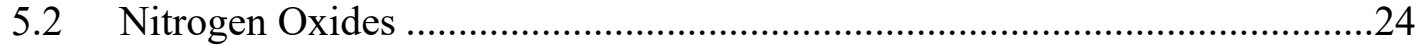

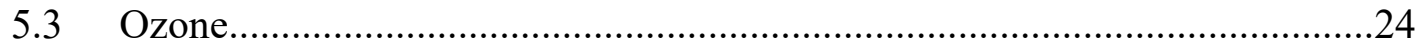

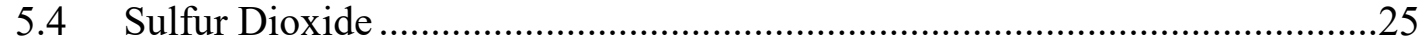

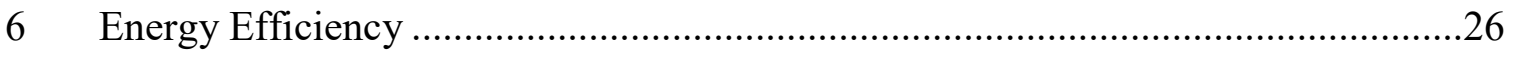

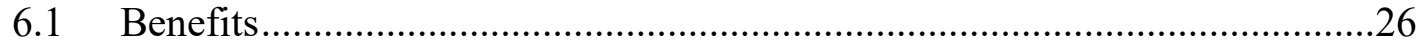




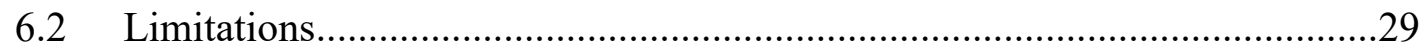

6.3 Illinois Energy-Efficiency Portfolio Standard for Electricity Generation......29

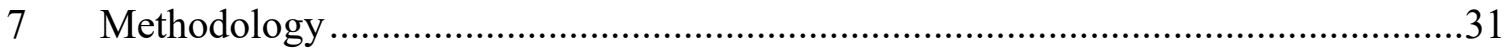

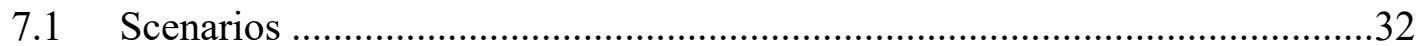

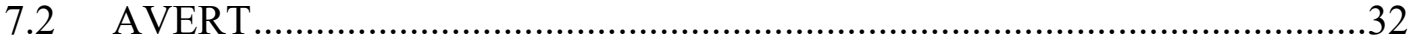

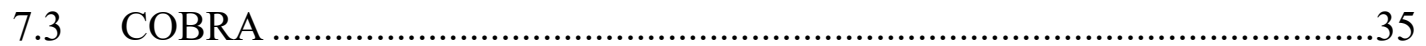

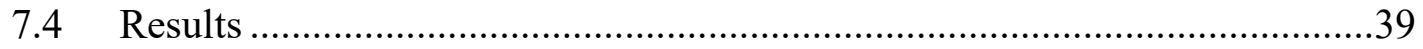

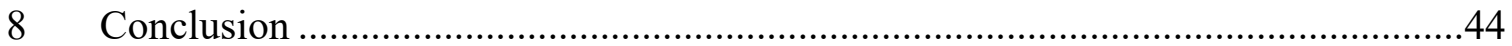

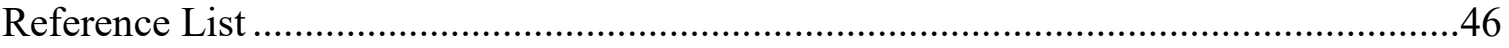

Appendix A. $\quad 2014$ Illinois Energy Consumption Flowchart............................. A-1

Appendix B. $\quad$ Operating Illinois Coal Power Plants...........................................

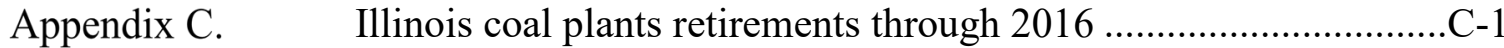

Appendix D. The NAQQS Table …..................................................... D-1

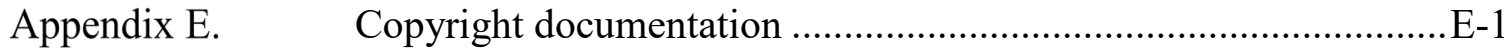




\section{List of figures}

Figure 3.1 Coal relative content in Illinois energy mix (Source: EIA-923 Form)..............

Figure 3.2 Coal generated electricity. (Source: EIA State Historical Tables) .................... 7

Figure 3.3 Illinois coal power plants. (Source: EIA's State Profile Overview) .................9

Figure 4.1 Types of air pollutants by the origin source. (Source: Figure by author)........13

Figure 4.2 Comparative particle sizes. (Source: EPA, Particulate Matter Basics) ............15

Figure 4.3 The ground ozone formation. (Source: EPA, Ground-level ozone basics)......17

Figure 4.4 $\mathrm{PM}_{2.5}$ concentrations trend in Ohio Valley. (Source: Figure by author, data by EPA Particulate Matter Trends) ...........................................................................19

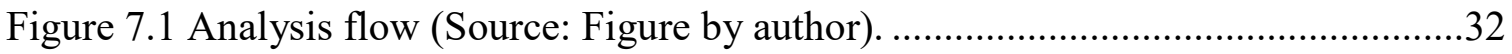

Figure 7.2 Map of AVERT regions. (Source: EPA's AVERT Tutorial)..........................34

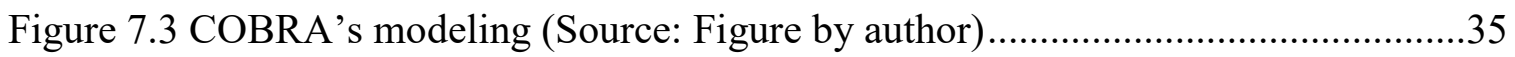

Figure 7.4 Hypothetical dispatch curve for summer 2011. (Source: The U.S. EIA Electric

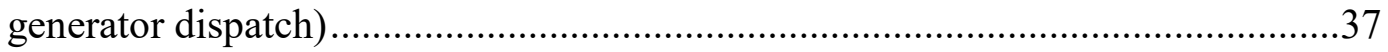

Figure 7.5 Hypothetical daily electric load curve (Source: Figure by author). .................37

Figure 7.6 Displaced Electricity Generation (MWh) for 2019 „....................................41 


\section{List of tables}

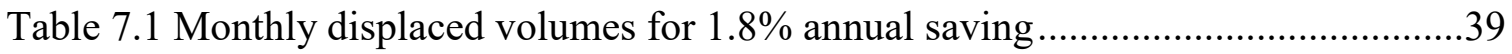

Table 7.2 Monthly displaced volumes for $2.0 \%$ annual saving ...................................40

Table 7.3 Annual displaced volumes and percent change for two scenarios....................42

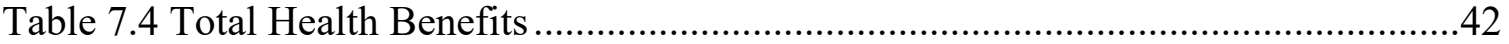

Table 7.5 Difference in health benefits between $1.8 \%$ and $2.0 \%$ annual savings ............43 


\section{List of abbreviations}

AVERT AVoided Emissions and geneRation Tool

COBRA CO-Benefits Risk Assessment

CO Carbon oxide

EEPS Energy-Efficiency Portfolio Standards

ICC Illinois Commerce Commission

IDC Illinois Department of Commerce

IECC International Energy Conservation Code

$\mathrm{NO}_{\mathrm{x}}$ Nitrogen oxides

$\mathrm{PM}_{2.5}$ fine particulate matter

RECS Residential Energy Consumption Survey

$\mathrm{SO}_{2}$ Sulfur Dioxide

U.S. DOE Department of Energy

U.S. EPA Environmental Protection Agency 


\begin{abstract}
A growing body of research has established the connection between emissions from fossil fuels and severe impacts on human health, such as asthma attacks in children and adults and chronic cardiovascular problems. This work evaluates in monetary terms the implementation of two energy-saving scenarios. Illinois, as a state with high coal electricity generating content, has been chosen as a case study to quantify the impacts brought up by air pollution on public health. The potential benefits of improved air quality and health are the considered results of implemented energy efficiency technologies. This report is a culmination of a summer internship project at the Midwest Energy Efficiency Alliance that links emissions, public health, and energy efficiency practices for commercial and residential buildings. Using Environmental Protection Agency's (EPA) AVoided Emissions and geneRation Tool (AVERT) and CO-Benefits Risk Assessment (COBRA) tools demonstrates that increased compliance with energy-efficiency portfolio standard (EEPS) by $0.2 \%$ will reduce $\mathrm{PM}_{2.5}$ emissions by 8.8 tons. The reduction contributes to an additional 1.2-3.2 million US dollars saved from avoided health impacts.
\end{abstract}




\section{Introduction}

Buildings are significant consumers of energy worldwide and in the United States. The U.S. Energy Information Agency (EIA) periodically conducts surveys to evaluate the condition of the residential and commercial buildings. According to the 2015 Residential Energy Consumption Survey, there were 18.1 million housing units in the East North Central (ENC) census division (EIA, 2018). The ENC is comprised of 5 states: Illinois, Indiana, Michigan, Ohio, and Wisconsin (U.S. Census Bureau, n.d.). The 2015 RECS indicates that $51.5 \%$ of Midwestern housing units were adequately insulated, and about $17 \%$ of houses were poorly insulated. Therefore, one of the consequences of existing insulation levels is increased energy consumption. For example, Illinois households used 44\% more energy per home than the U.S. average in 2009 (EIA, 2009).

Another side aspect is the excessive emission of pollutants into the atmosphere, which can be avoided through improved efficiency in the performance of residential and commercial buildings. Air pollution caused by emissions from coal power plants has been an acute environmental problem around the globe. This problem exists in regions where coal represents a significant share in the energy mix. In addition to causing environmental damage, air pollution leads to negative impacts on public health.

The report will try to describe the current situation in the context of Illinois. To do this, the next chapter explains the current situation in the building sector and the relationship with air pollution in the world and the USA. The third chapter characterizes the Illinois' energy profile. This part discusses the role of coal in the state's energy profile, electricity production, and the current status of coal plants. The fourth chapter focuses on air pollution, focused on six types of pollutants, their features, and sources, which are the pollutants regulated by the Clean Air Act (CAA). This law is considered one of the essential regulatory mechanisms, the implementation of which has contributed to a significant decrease in the air pollutant concentration (need reference here to provide evidence for this claim). The fifth chapter is about the health impacts of coal as an electricity generating commodity. The chapter presents the results of epidemiological and toxicological studies 
conducted over the past decades for more common pollutants. The sixth chapter deals with energy efficiency, related benefits, and limitations.

Coal plants are one of the main sources of air pollution (MacIntosh \& Spengler, 2008). Consequently, lowering electricity demand may reduce emissions into the air. Improved air quality has positive consequences, one of which is enchancement of the well-being of people, especially those who are sensitive to pollutants. The goal of the report is to present an estimatation of the resulting public health benefits of reductions in $\mathrm{PM}_{2.5}$ levels and then monetize the health benefits using tools proposed by EPA. The methodology chapter goes into detail on which tools were used to perform the assessment. Three steps assist in quantifying emissions and the health benefits of reduced coal consumption. The first step selects hypothetical scenarios for annual electricity savings. Scenarios are based on what has been achieved and what is possible. In the case of the analysis, these two scenarios are $1.8 \%$ and $2.0 \%$ electricity annual savings. For the second step, these estimates are entered into the EPA's AVERT tool to calculate the avoided amounts of the pollutants. For the last step, the pollution reductions from AVERT are inserted into COBRA. COBRA presents the economic effects of avoided emissions. The final part is a chapter that sums up the results with subsequent recommendations. 


\section{Overview}

Electricity plays an important role in economic growth by speeding up technological progress and industrialization (need ref. to support claim). The availability of this form of energy has led to an increase in income levels in many parts of the world. Particularly, Western European countries have experienced a sixteen-fold increase in real incomes per capita since the Industrial Revolution began (Maddison, 2003, p. 262).

One of the commonly used indicators in determining the rationality of the use of energy resources is the energy intensity of the economy. Energy intensity reflects how efficiently a country's economy uses energy resources. In other words, it calculates how much a bit of energy benefits the economy. High energy intensities express a high cost or price of converting energy into the gross domestic product (GDP). Low energy intensity indicates a lower price or cost of converting energy into GDP. For North America, each unit of energy as of 1990 brought forth 3.5 times more real dollar of GDP than it had done in 1850 (Grübler et al., 1996). There are several end-use sectors of the economy for which energy consumption is considered, including residential and commercial buildings, industrial, and transportation.

Residential and commercial buildings, if combined, are the largest consumers of energy worldwide and will continue to remain an important source of demand without technological improvements and well-structured policies. According to the International Energy Agency (IEA), residential and commercial sectors of the global economy consume over $30 \%$ of global total final energy and half of the produced electricity (IEA, 2015, p. 52). Currently, burning fossil fuels generates about $60 \%$ of global electricity, resulting in the residential and commercial sectors being responsible for almost $30 \%$ of global carbon dioxide emissions. A similar situation with overall energy consumption is observed in the United States. According to EIA, about 39\% of U.S. total primary energy was consumed by the residential and commercial sectors in 2017, and two-thirds of this share is used in the production of electricity (EIA, 2015). There are approximately 112 million households and commercial buildings in the U.S., and their total energy consumption equals $38.3 * 10^{15}$ 
BTU (or roughly 1.4 billion metric tons of burned coal). Continuing rising trends in buildings stock causes an increase in the amount of newly built power plants (U.S. Department of Energy, 2008). As a consequence, there has been an increase in the sale of electricity from 1985 to 2006, and the building sector accounted for $87 \%$ of it (ibid.). As for Illinois, according to the 2009 RECS, the state's households use 129 million BTU of energy per home, and the value is $44 \%$ higher than the U.S. average (EIA, 2009).

Several solutions can meet the sector's growing needs. One of them is the application of energy-efficient techniques. Various studies confirm the economic viability of implementing energy-saving programs in buildings, particularly in the residential sector, as a mitigation measure due to cost-effectiveness. Thus, considerable efforts in policymaking were made during the last 20 years to slow down energy demand growth in buildings.

Legislatures in nearly every state have considered a variety of energy efficiency policies (Dixon et al., 2010). While states have made noteworthy headway in increasing energy efficiency, there is still room to develop more in-depth practices. Policymakers have invigorated statewide initiatives to modernize efficiency efforts, target particular sectors or demographics, and boost economic investments. However, the costs of the program implementation are well recognized, but benefits are often not fully recognized (Levy et al., 2016). There is a perception that costs can exceed benefits because the way the energyefficient programs are being measured does not do a good job of incorporating and monetizing the non-energy impacts. In particular, this perception is because the so-called externalities of electricity generation from fossil fuels, coal particularly, are the burdens to society, and they are not included in the electricity's monetary price.

Air pollution caused by emissions from coal power plants has been an acute environmental problem around the globe. This problem exists in regions where coal represents a significant share in the energy mix. In addition to causing environmental damage, air pollution leads to negative impacts on public health. 
Energy use reduction can bring many direct benefits, ranging from reduced electricity bills to a reduction in global temperature growth. According to the U.S. Department of Energy, if the owners of residential houses and commercial premises use the recommended codes, $\$ 126$ billion will be saved by 2040 . Additionally, 841 million metric tons of carbon dioxide emissions will not be added to the atmosphere by 2040 (U.S. Department of Energy, 2018).

Historically, energy efficiency programs have been implemented by energy utility providers. However, energy efficiency policies sometimes face resistance resistance since they incurr additional costs to utilities and customers. This report is an attempt to quantify the non-energy related benefits of implementing energy-efficient programs. The objective of the report is to establish an association between energy consumption, air pollution concentrations, particularly due to particulate matter (PM 2.5), and concluding effects on public health in the Illinois counties where coal plants are situated. Understanding the nexus between energy consumption, current technologies, and related impacts on health provides valuable input to the environmental and energy policy-making process. 


\section{Illinois Energy Profile}

Illinois plays an important role in the U.S. economy, ranking among other US states in terms of GDP and accounting for 4.2\% of the nation's total GDP (Bureau of Economic Analysis, 2019). The state's economic importance is attributed to its role as a centrally located transportation hub. A significant amount of crude oil and natural gas is transported through the state. The high level of economic activity and well-developed industrial infrastructure make Illinois one of the largest energy-consuming states in the country.

Over $90 \%$ of mined coal in Illinois goes to utilities in Illinois and other states to generate electricity. The remainder is used for other types of customers (petrochemicals, metallurgy, etc.). Approximately $30 \%$ of the state's electricity comes from coal. Normally, one pound of Illinois coal generates a little bit more than one kilowatt-hour of electricity (Illinois Coal Association, n.d.).

Over a long time, coal has been a stable fossil fuel in meeting U.S. consumers' energy needs and thereby exuding a significant influence on the development of American society. Beginning in the 19th century, coal was an indispensable premise of technological progress and industrialization (Höök \& Aleklett, 2009). For instance, Chicago was becoming an industrial center at the end of the $19^{\text {th }}$ century with the help of centralized electricity generating units (EGUs). The station on the west bank of the Chicago River on Harrison Street might serve as an example. The station began operating in August 1894 with a revolutionary capacity of 6.4 MW, which then doubled in the following ten years (Hogan, 1986). Over the next twenty years, three larger stations were built - on Fisk Street and Quarry Street, as well as Northwest station (ibid). The use of coal as a critical fuel to meet increasing electricity demand was particularly justified in Illinois, given the state's significant reserves (Platt, 1991).

The share of this resource in the energy mix of the state has been peaking almost $50 \%$ over the past two decades. However, the decrease in coal relative content has occurred over the past few years. The coal share, among other sources in electricity production from 2001 to 
2018, is shown in Figure 3.1. For example, in December 2018, monthly coal consumption by all sectors for electricity production amounted to 2,815 thousand tons. In December 2019 , consumption decreased by as much as $36 \%$, reaching a value of 1,809 thousand tons, which made it possible to generate 3,097 MWh of electricity. (EIA, 2020). In quantitative terms, the production of electricity by burning coal for the 2001 to 2018 period is shown in Figure 3.2.

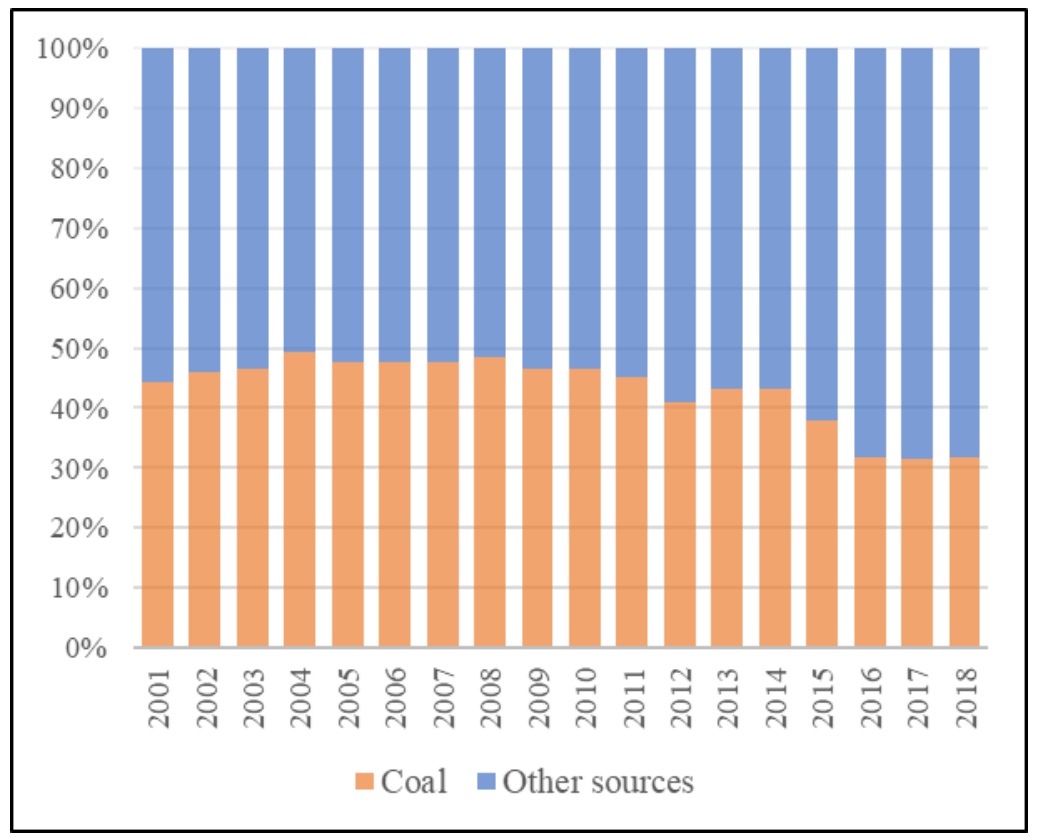

Figure 3.1 Coal relative content in Illinois energy mix (Source: EIA-923 Form)

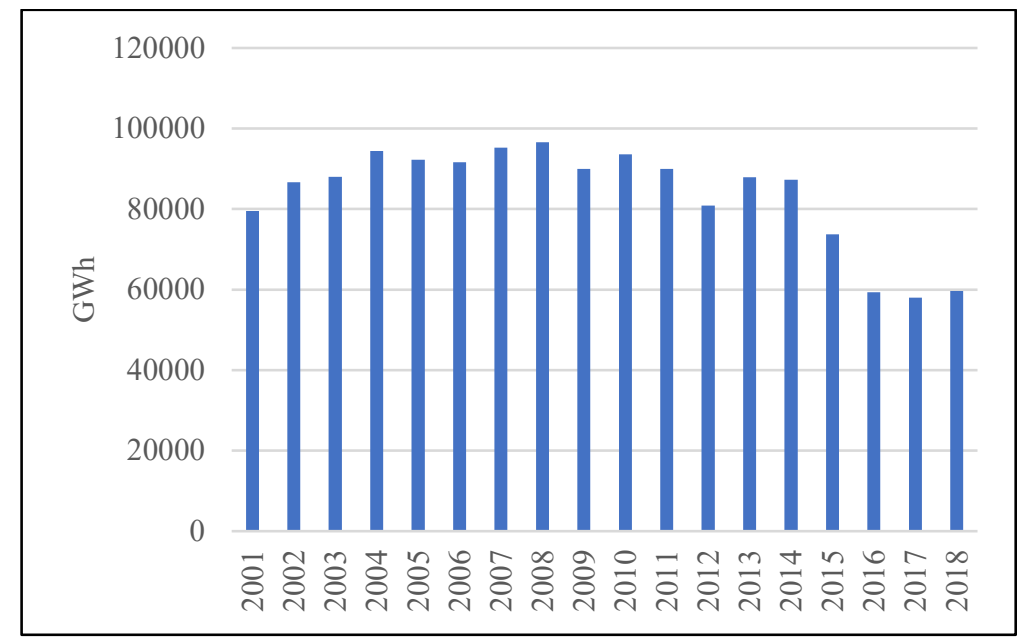

Figure 3.2 Coal generated electricity. (Source: EIA State Historical Tables) 
State energy consumption by sector as of 2017 is as follows: $30.4 \%$ industrial use, $26.0 \%$ is for transportation, $23.0 \%$ residential, and $20.6 \%$ commercial sectors (EIA, 2019). For residential buildings, electricity is used for appliances, electronics, and lighting, as over $80 \%$ of Illinois households use natural gas to heat their homes. On average, each household consumes a little more than 10 thousand kilowatt-hours per year while spending about 1,250 dollars (EIA, 2009).

\subsection{Illinois coal}

From the supply side, the state has the third-largest coal reserves in the country, with about 200 billion short tons of the carbonaceous commodity. However, only about one-fifth of the reserves are economically recoverable with current methods (Hansel, n.d.). As of 2018, state coal production was 49 million short tons, or $6 \%$ of U.S. total coal production (EIA $2018,2020)$. According to EIA, approximately $20 \%$ of produced coal is consumed within the state to provide electricity and other industrial activities, including coking. The rest of the mined coal is exported to other US states and abroad.

Coal combustion has several substantial drawbacks. In addition to contributing to a rise of the carbon dioxide $\left(\mathrm{CO}_{2}\right)$ concentration in the atmosphere, this type of fuel contains various impurities, for example, sulfur. In terms of quality, coal of Illinois fields is typically characterized by high sulfur content. Illinois State Geological Survey conducted multiple investigations concerning sulfur presence in local coal. According to the study, total sulfur in the samples ranges from low of less than $0.5 \%$ to high values varying between 5.0 to $6.0 \%$ (Stevenson et al., n.d.). The high-sulfur content of the Illinois coal basin demands special technologies to employ to meet the environmental requirements of the Clean Air Act (CAA). Installation of additional equipment that can conform with the regulation costs utilities, and it is a common practice among utilities to combine local coal with coal brought from other states with lower sulfur content. 


\subsection{Coal power plants in Illinois}

As of 2019, nineteen coal power plants were operating in the state (Figure 3.3). The total capacity of operating stations is 14,305.3 MW. Between 2019 and 2024, it was planned to decommission five power plants, four of which should stop working in December 2019, and one at the end of 2024 (Table A.1). Typically, power stations use several boilers of different capacities, which can be used depending on the load. These units are put into operation and disabled at different times. Over the past fifteen years, eighteen units of eleven coal stations have been disabled, with a total capacity of 4,650 MW (Table A.2).

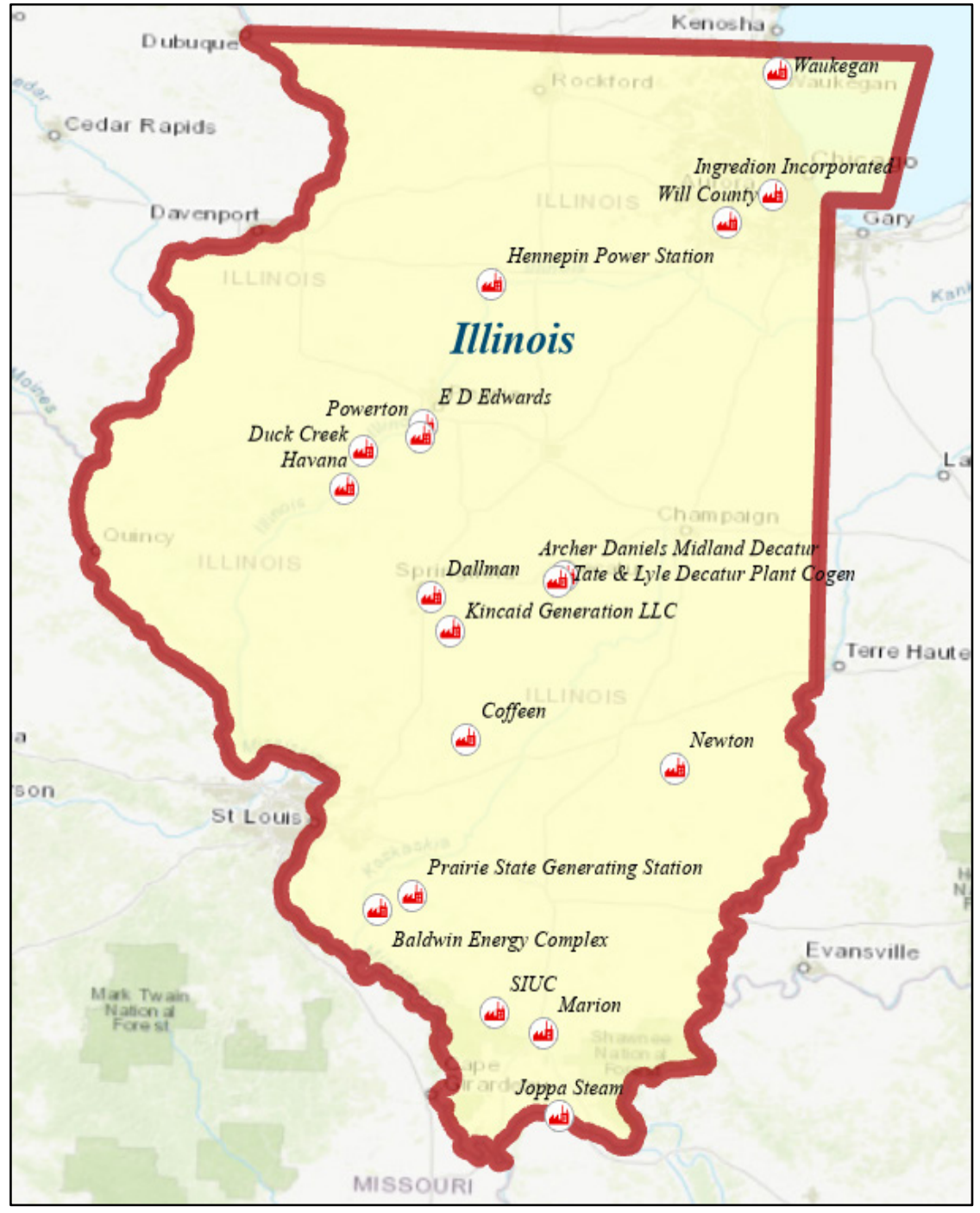

Figure 3.3 Illinois coal power plants. (Source: EIA's State Profile Overview) 
All plants that are planned to be closed came online in the 60 s and early 70 s. The following Figure 3.4 depicts the main parameters of existing coal-powered stations. The circumference of the station represents the net generation in 2019. From the information provided in the figure, it follows that a cluster of old stations with high capacities is located on the left side of the plot. Two-third of the coal power stations have been in operation for more than 40 years. Only three stations were introduced relatively recently.

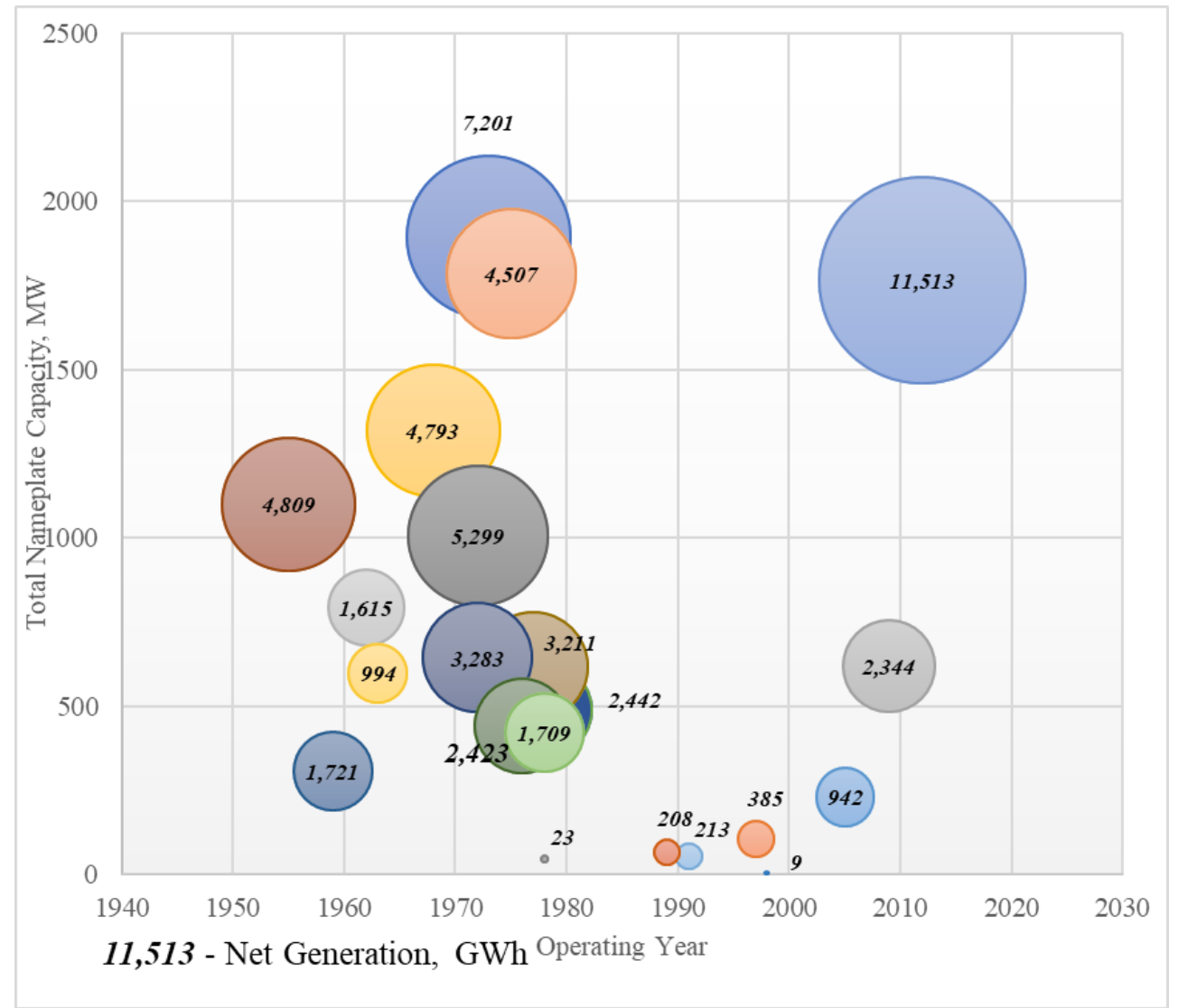

Figure 3.4 Existing coal power plants characteristics. (Source: EIA-923 and EIA-860)

\subsection{Illinois Regulatory Framework for Coal Powered Electricity Generation}

The Illinois Power Agency Act (IPAA) that was enacted in August of 2007 shaped energy efficiency and demand response programs in Illinois. Under the requirements of the Act, electric utilities with one hundred thousand or more customers require demonstrating annual electricity savings reduction. The goal was to provide a gradual annual reduction in electricity sales equal to $0.2 \%$ of the previous year's electricity sales from 2008-2009 to 
2016. By 2016, a gradual annual increase should have reached a $2 \%$ level. The level of electricity savings remains at this value for all subsequent years. According to the ACEEE, in 2018, net incremental electricity savings in Illinois were equal to $1.66 \%$ (Berg et al., 2019). Utilities are obliged to file an energy efficiency and demand response plans with the Illinois Commerce Commission (ICC) every three years. Typically, energy savings goals are achieved through end-use efficiency programs. The 2016 Future Energy Jobs Bill (SB2814) required both Ameren and ComEd to allocate \$25 million every year through 2030 to income-eligible efficiency programs.

Illinois also mandates that $25 \%$ of the electricity used in the state shall be generated by clean coal facilities by January 1, 2025. The Illinois Power Agency Act definition for clean coal facility is:

"[E]lectric generating facility that uses primarily coal as a feedstock and that captures and sequesters carbon dioxide emissions at the following levels: at least $50 \%$ of the total carbon dioxide emissions that the facility would otherwise emit if, at the time construction commences, the facility is scheduled to commence operation before 2016 , at least $70 \%$ of the total carbon dioxide emissions that the facility would otherwise emit if, at the time construction commences, the facility is scheduled to commence operation during 2016 or 2017 , and at least $90 \%$ of the total carbon dioxide emissions that the facility would otherwise emit if, at the time construction commences, the facility is scheduled to commence operation after 2017." 


\section{Air Pollution Definition}

Air pollution can be defined from several perspectives, including those that are regulatory and practical (Phalen, 2013). A practical perspective defines an air pollutant as any substance that disadvantageously interferes with an object, a process, or a person and thus reduces the value. For example, in production requiring extreme purity (manufacturing a high-tech product), even a speck of dust can significantly degrade product quality. Another illustration is high humidity that may decay an ancient artifact of high historical value. An air pollutant from a regulatory perspective has a more specific definition. Air pollutant is a substance the presence of which, above safe permissible standards, poses harmful effects on plants, animals, and humans. It also worsens the climate, visibility, and other aspects. The regulatory body determines the criteria by which an element is perceived as a pollutant. The principal agency that regulates levels of aerodisperse systems on a federal level in the United States is the U.S. Environmental Protection Agency.

Air pollutants can be classified by the nature of their origin (Figure 4.1). Natural pollutants in which sources are volcanic eruptions, forest fires, and other natural phenomena. These emissions are in the main generated at distant or barely populated locations. Another type is human-made or anthropogenic air pollutants. These substances are products of human activities, and it can be said with confidence that any human activity in one way or another produces air pollution. Further subdivision of this group is composed of stationary (e.g., conventional electric utilities, chemical manufacturing, construction) or mobile (e.g., automobiles, aircraft) sources. Each member of the list has its fingerprint, or in other words, a set of pollutants it emits. 


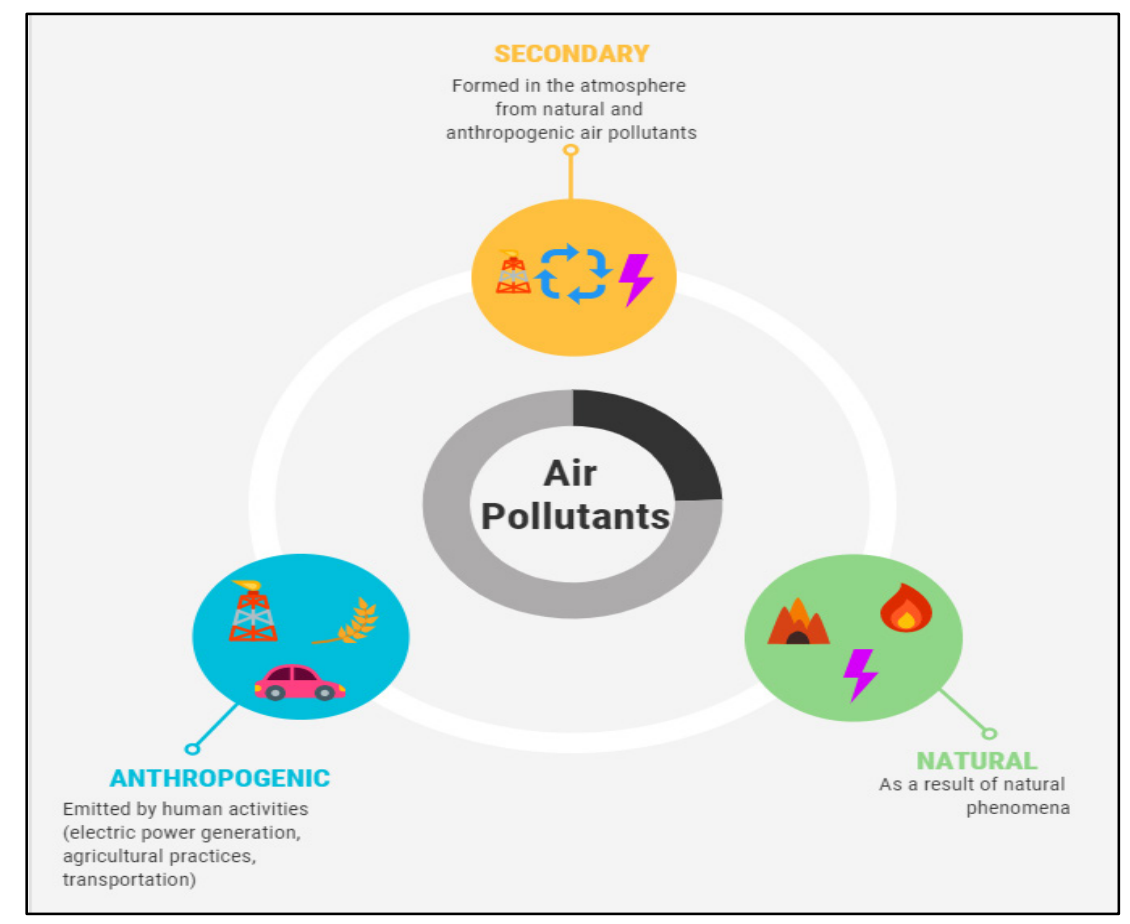

Figure 4.1 Types of air pollutants by the origin source. (Source: Figure by author)

\subsection{Types of criteria air pollutants}

Six air pollutants defined by the EPA as criteria air pollutants under the Clean Air Act (CAA) and regulations thereunder will be briefly described in this chapter, as well as their origin and distribution mechanisms. The discussion here includes particulate matter, carbon monoxide $(\mathrm{CO})$, lead, nitrogen dioxide $\left(\mathrm{NO}_{2}\right)$, ozone $\left(\mathrm{O}_{3}\right)$, and sulfur dioxide $\left(\mathrm{SO}_{2}\right)$.

\subsubsection{Carbon monoxide (CO)}

Carbon monoxide is a colorless, tasteless, and odorless gas. There are natural and anthropogenic sources of $\mathrm{CO}$ emission into the Earth's atmosphere. Under natural conditions, $\mathrm{CO}$ is formed during the incomplete anaerobic decomposition of organic compounds and the combustion of biomass, mainly during forest and steppe fires. Carbon monoxide is formed in the soil, both in biological (excretion by living organisms) and nonbiological ways. In the atmosphere, $\mathrm{CO}$ is the product of reaction chains involving methane and other hydrocarbons. The human-made CO sources are in the fumes of carbon-based 
fuels such as wood, coal, and gasoline. The significant source of carbon monoxide to ambient air is cars, trucks, and other vehicles using internal combustion engines, especially at insufficient temperatures or poor air supply system settings.

Very high levels of $\mathrm{CO}$ concentrations may be reached in enclosed environments rather than outdoors. Fireplaces, stoves, and chimneys, either with back-drafting or poor ventilation, could be potential culprits for leakage. According to EPA, average levels for homes without gas stoves fluctuate in 0.5 to 5 parts per million range. For homes with improperly adjusted stoves, the levels can reach $30 \mathrm{ppm}$ or higher (EPA, Indoor Air Quality, n.d.).

The toxic effect of carbon monoxide occurs because it binds to blood hemoglobin more strongly than oxygen, thus blocking the processes of oxygen transportation and cellular respiration. All people are at risk for CO poisoning yet such social groups as infants, the elderly, and people with chronic heart disease, anemia, or respiratory problems are generally more at risk than others

\subsubsection{Lead}

The main emitters of lead in the air are ore and metals processing and piston aircraft operating on leaded aviation fuel. This kind of airplanes has piston-powered engines that use 100 octane low-leaded fuel. According to the Federal Aviation Administration (FAA), there were more than 200,000 piston-engine aircraft in the United States as of 2010 (FAA, 2011). Other sources are waste incinerators, utilities, and lead-acid battery manufacturers.

Lead compounds are known for their high toxicity and persistence. Infants, children, and pregnant women are especially susceptible to lead poisoning. It harms the whole body, but the central nervous, hematopoietic, and digestive systems are especially susceptible to damage. The metal gradually accumulates in the organs, without visible manifestations, and the consequences can occur after only months and can last for years if not permanently (EPA, Lead Air Pollution, n.d.). 


\subsubsection{Particulate Matter (PM)}

Particle pollution is a complex blend of small liquid or solid specks suspended in the atmosphere. PM includes many different chemical components, such as secondary sulfate, nitrate, black carbon, mineral dust, soot, and fly ash. Some part of these particles is released directly from various sources like motor vehicles, power plants, burning. In contrast, others are the result of intricate chemical and mechanical interference in the air. Thus, depending on the source and other conditions, these properties vary with location and time. Generally, due to the complexity of the category, PM is divided into three subcategories according to the diameter. The first category is ultrafine particles (UFP) whose diameter is equal to or less than 0.1 micrometers $(\mu \mathrm{m})$, then goes fine particles with a diameter equal to or less than $2.5 \mu \mathrm{m}\left(\mathrm{PM}_{2.5}\right)$ and larger coarse dust particles are 2.5 to $10 \mu \mathrm{m}$ in diameter $\left(\mathrm{PM}_{10}\right)$. Figure 4.2 depicts the particle size, relative to the common grain of beach sand and hair thickness. As can be seen from the illustration below, their microscopic sizes make them able to penetrate deep into the human respiratory tract. Ambient PM levels are determined by seasonal patterns, as well as geographical and meteorological conditions. Concentrations can also vary depending on daily weather conditions such as wind speed and precipitation.

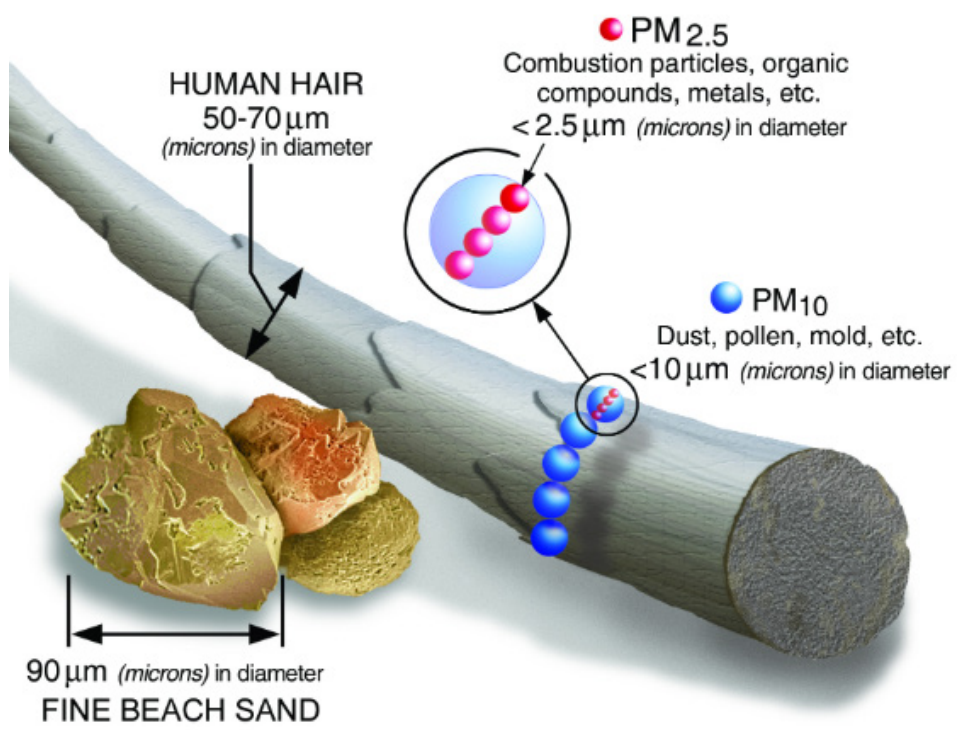

Figure 4.2 Comparative particle sizes. (Source: EPA, Particulate Matter Basics) 


\subsubsection{Nitrogen dioxide $\left(\mathrm{NO}_{2}\right)$}

$\mathrm{NO}_{2}$ is a gas of yellow-brown color, with a pungent odor. However, it is mostly odorless at those concentrations in which it is found in the atmospheric air of large cities. It has a pronounced irritant effect on the respiratory tract and a general toxic effect. $\mathrm{NO}_{2}$ is a derivative of the combustion processes such as car exhaust, power plant emissions, solid waste incineration, gas ignition and is commonly found in the atmosphere in close association with other significant pollutants. $\mathrm{NO}_{2}$ also converts from $\mathrm{NO}$ by photochemical reaction with oxygen. Since the content of $\mathrm{NO}_{2}$ is easier to measure, it often acts as the basis for an indirect analysis of a variety of pollutants, as well as an assessment of the quality of atmospheric air in general.

As with other pollutants, the spread of $\mathrm{NO}_{2}$ is subject to meteorological conditions. Light wind, lack of precipitation, and vertical mixing lead to a deterioration of the circumstances for dispersion of pollutant emissions in the air and their accumulation in the surface layer of the atmosphere. NO2 plays an important role in the formation of the smog that reduces visibility and aesthetics.

\subsubsection{Ozone $\left(\mathrm{O}_{3}\right)$}

Ozone is a gas made up of three oxygen atoms and a robust reactive agent. It is naturally found in the upper layer of the atmosphere between the troposphere and stratosphere, where it protects against ultraviolet radiation from the sun. On the ground, $\mathrm{O}_{3}$ distresses the living environment. This type of $\mathrm{O}_{3}$ in the lower atmosphere originates when industrial operations and vehicle exhausts containing nitrogen oxides $\left(\mathrm{NO}_{\mathrm{x}}\right)$ and volatile organic compounds (VOC) come in contact with sunlight and heat (Figure 4.3). Ground-level $\mathrm{O}_{3}$ is called "smog" and is harmful to breathe. $\mathrm{O}_{3}$ reacts with other molecules because of its high activity. As it can be concluded, in warm seasons, $\mathrm{O}_{3}$ levels are higher than during the colder temperatures. Thus, concentrations for ozone can increase during sunny and hot days, while motionless air masses may increase both $\mathrm{O}_{3}$ and $\mathrm{PM}$ levels. 


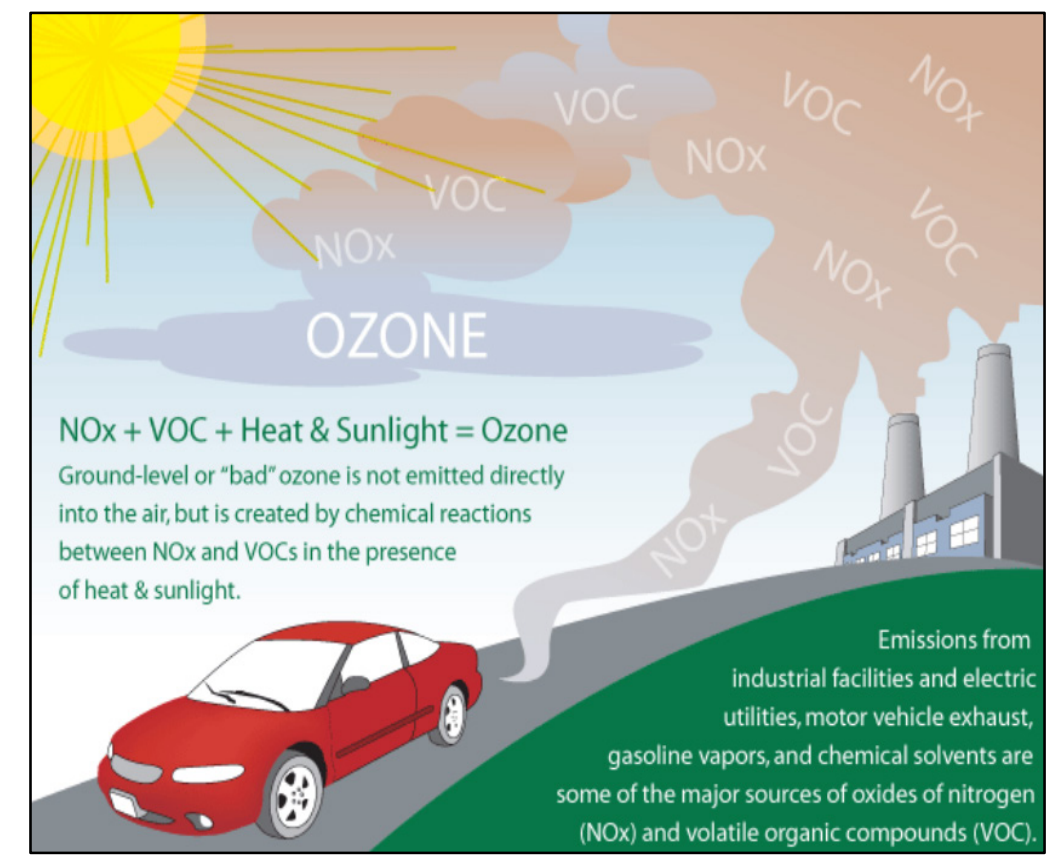

Figure 4.3 The ground ozone formation. (Source: EPA, Ground-level ozone basics).

\subsubsection{Sulfur dioxide $\left(\mathrm{SO}_{2}\right)$}

$\mathrm{SO}_{2}$ is a colorless gas with a characteristic pungent and disturbing odor characteristic of hydrogen sulfide. In its pure form, the substance is poisonous. $\mathrm{SO}_{2}$ can be released as a result of the operation of thermal power plants during the combustion of brown coal and fuel oil, and it is also can be formed during the smelting of mineral ores containing sulfur. Large emissions of sulfur occur in the oil and gas sector because hydrogen sulfide accompanies the process of extraction of these commodities. Typical processes for the formation of dispersed aerosols - grinding of coal, wind erosion of the soil. Volcanic activity is the main source of emissions of this compound into the atmosphere regarding the natural distribution paths.

$\mathrm{SO}_{2}$ dissolves in water; at the minus temperature, it becomes liquid and forms sulfuric acid, which, being present in rainfalls, damages vegetation, agricultural land, and other objects. The problem of acidic rains was of acute importance in the last decades of the previous century in the elimination of which significant results have been achieved (Grennfelt et al., 2019). 


\subsection{Clean Air Act (CAA) as a Tool for Protecting Public Health}

Air quality regulation at the U.S. federal level has been gradually enhanced since the introduction of the CAA in 1970. Even though this was not the first federal law regarding the pollution of ambient air, it is considered the most significant achievement in the field of air quality monitoring and enforcement authority (Schmalensee \& Stavins, 2019). The CAA Amendments enacted in 1990 imposed constraints on the use of high sulfur coals in power stations, causing caused important changes that reinforced regulations on four main provisions: acid rain, ozone depletion, toxic air emissions, and urban air pollution (Ross et al., 2012). The Amendments had a robust negative influence on the demand for high-sulfur coals mined mainly from the interior regions of the US during the following years (O'Brien, 1997). The implemented actions led to changes in air quality for the better. Even though that ambient concentrations of several pollutants have dropped during the last decades, the advancement of innovative strategies for efficient reduction of emissions and health impacts will bring in considerable additional benefits. By speaking of effective methods, it means aiming either on the lowest mitigation costs or the greatest marginal damages (Goodkind et al., 2019).

The oversight body responsible for monitoring emissions is the U.S. Environmental Protection Agency (EPA). The agency keeps track of a range of emissions data, including how much of each pollutant is emitted from various pollution sources. The EPA is obliged by the CAA to set National Ambient Air Quality Standards (NAAQS) for each of 6 criteria air pollutants (CAPs) and the National Air Toxics Assessment (NATA) for 187 hazardous air pollutants (HAPs). These agents are counted to be harmful to public health and the environment. The NAAQSs are subjected to periodic review and possible revision at least every five years based on new scientific evidence. NAAQSs denote two types of criteria for six pollutants: primary pollutant criteria that protect human health and secondary

pollutant criteria for categories like damage to crops, livestock, or reduced visibility (Table A.3). Unlike the CAPs, toxic constituents may be added or removed from the HAPs' listing, and they are not subjects to a mandatory five-year review. For example, the initial HAPs catalog consisted of 189 toxic agents. 


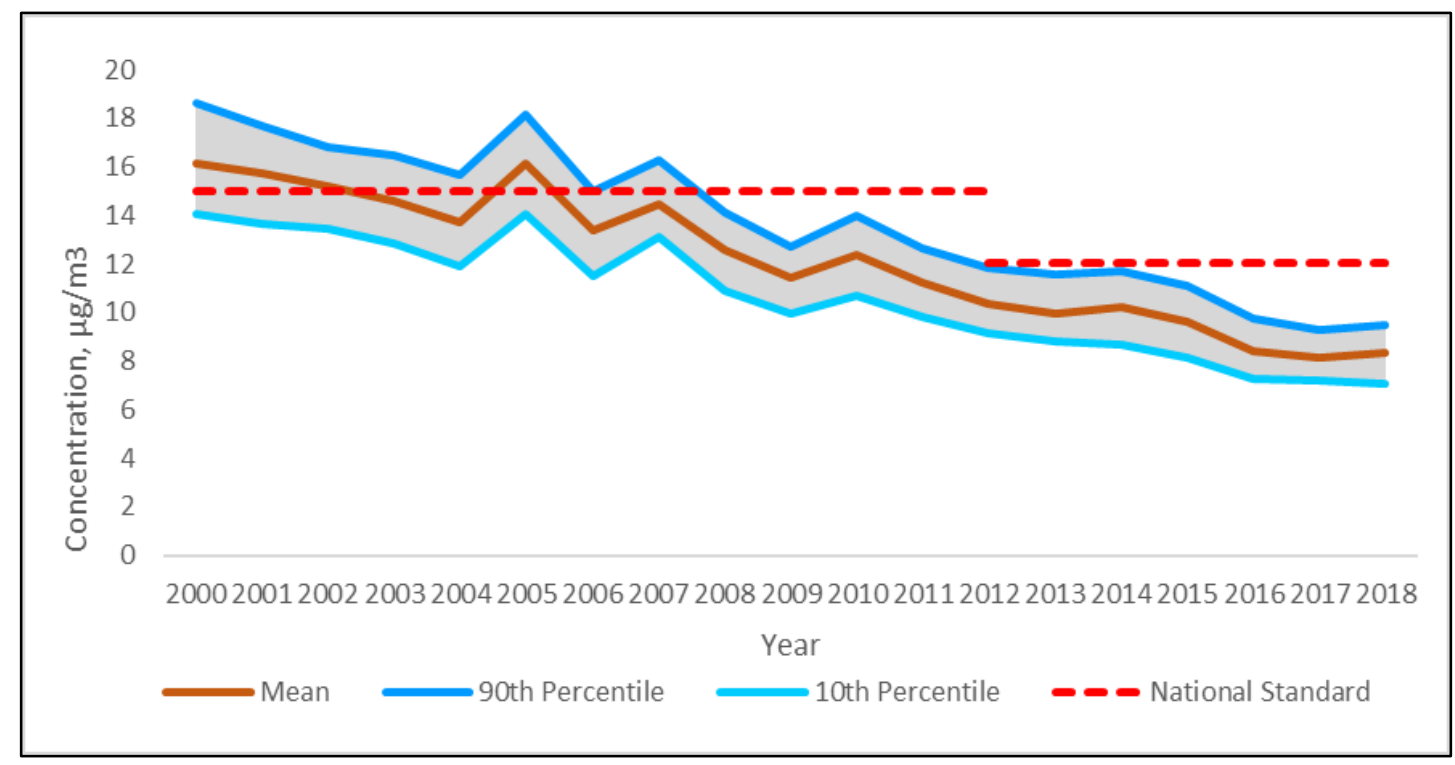

Figure 4.4 $\mathrm{PM}_{2.5}$ concentrations trend in Ohio Valley. (Source: Figure by author, data by EPA Particulate Matter Trends)

Figure 4.4 shows the trend within a 10 -year timeframe for 63 monitoring sites across the Central area. The area assigned by the National Oceanic and Atmospheric Administration (NOAA) and includes Illinois among the other six Midwestern states. Around $90 \%$ of sites have shown concentrations below the top line, while $10 \%$ of sites have demonstrated concentrations below the bottom line for this territory. A dotted line stands for the primary annual $\mathrm{PM}_{2.5}$ national air quality standard prior to December $14^{\text {th }}, 2012$. The standard was set up at 15 micrograms per cubic meter $\left(\mu \mathrm{g} / \mathrm{m}^{3}\right)$. In 2012, the EPA strengthened the annual standard by decreasing the rate to $12 \mu \mathrm{g} / \mathrm{m}^{3}$ based on the 3-year average of annual mean fine particle concentration. The daily standard for this category had remained the same since 2006 and was equal to $35 \mu \mathrm{g} / \mathrm{m}^{3}$ for a 24-hour average. The decision was made according to new evidence that was based on more than 300 new epidemiological studies. According to the results of these studies, it turned out that even though in some parts of the USA, the concentration of $\mathrm{PM}_{2.5}$ did not exceed the norms of the old standard, $\mathrm{PM}_{2.5}$ still had a negative impact on public health (EPA, 2016). The revised $\mathrm{PM}_{2.5}$ standard became effective on March 18, 2013. 
Despite the progress in air quality enhancement, in 2018, there were about 137 million people nationwide who lived in counties with pollution levels above the primary NAAQS (EPA, 2019a). Thus, considering that fluctuations occur due to other factors, the problem of air quality remains relevant. Particularly, approximately one-third of Americans were exposed to levels of ozone that exceeded the national standard in 2015 (Reidmiller et al., 2018).

A recent study conducted by the National Bureau of Economic Research confirms a surge in PM2.5. The study specifies three potential contributing factors to the worsening of air quality: more frequent wildfires, increased economic activity, and less stringent enforcement of federal regulations, such as the CAA (Clay \& Muller, 2019). The $\mathrm{PM}_{2.5}$ pollution level in the Midwest worsened by around $10 \%$ since 2016, according to the study.

Figure 4.5 exposes observation on the number of days with increased levels of pollutants in the Chicago Metropolitan Area. The value of 24-hour average for a "very unhealthy" level corresponds to a concentration of fine particles in the range of $150.5-250.4 \mu \mathrm{g} / \mathrm{m}^{3}$. "Unhealthy" category designates concentrations reaching the range of $55.5-150.4 \mu \mathrm{g} / \mathrm{m}^{3}$. For the latter group "unhealthy for sensitive groups," the concentration fluctuates between 35.5 and $55.4 \mu \mathrm{g} / \mathrm{m}^{3}$.

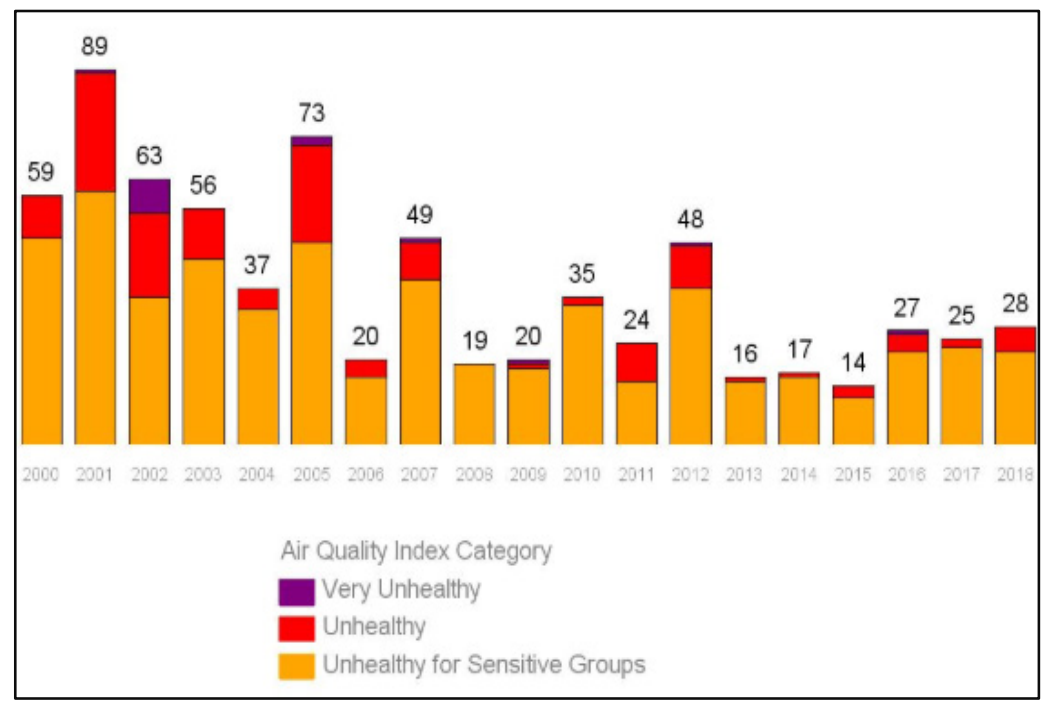

Figure 4.5 Number of days reaching unhealthy levels for sensitive groups and above for the Chicago Metropolitan Area. (Source: EPA A Look Back: Ozone and PM in 2018) 


\section{Health Impacts of Coal}

Coal-fired power plants give off 84 of the 187 hazardous air pollutants pinpointed by the U.S. EPA (National Library of Medicine, n.d.). The main group of by-products emitted during coal combustion is particular matter, nitrogen and sulfur oxides, carbon dioxide, mercury, arsenic, and other heavy metals. Ground-level ozone is not emitted directly from the plant's tall stack. Still, it is the result of further transformations: nitrogen oxides emitted from plants reach higher strata of the atmosphere where they, in combination with volatile organic compounds, form ozone. The U.S. energy sector accounts for $80 \%$ of $\mathrm{NO}_{\mathrm{x}}$ emissions and $96 \%$ of $\mathrm{SO}_{2}$, the major precursor of sulfate aerosol (Wuebbles et al., 2017).

Exposure to the pollutants may cause numerous health implications, including respiratory, cardiovascular, and nervous systems. These complications can increase the occurrence of chronic respiratory diseases, allergies, lethal pulmonological infections, lung cancer, stroke, and heart disease. Although everyone breathes air containing these substances, special risk groups are children, pregnant women, the elderly, and people with existing health complications. The latest annual report of the American Lung Association provides data that about 800 thousand people (pediatric and adult asthma) belong to the at-risk group in Illinois (Paul et al., 2019). Also, over half a million people with the chronic obstructive pulmonary disease can be added to this category (ibid.). At the same time, categories of people who are more susceptible to environmental conditions are also at risk, especially in situations where professional activities involve a long stay outside, such as landscapers, construction jobs, etc.

In 2009, Little Village Environmental Justice Organization, an NGO located in Illinois conducted a study. The purpose of the study was to find out whether the location of the coal stations in Illinois is determined by the level of income of the population and/or by the predominance of certain minorities. As it turned out, there were trends of placing the coal power stations predominantly within Latino communities (Armstrong \& Becerra, 2009). Additionally, the largest coal-burning stations were located in areas where about half of the population is below the poverty line (ibid). 
Another report made for a coalition of three organizations (National Association for the Advancement of Colored People, Indigenous Environmental Network, and Little Village Environmental Justice Organization) had a wider geography. The report confirms a similar trend of a disproportionate location of the coal power plants within the continental United States (Wilson et al., n.d.). Results of the study indicate that 75 coal power stations out of 378 had a unequal impact on low-income people and people of color from environmental justice perspective (ibid.). Thus, the proximity of coal stations carries an additional burden for these groups.

A different significant concern is ash and its storage. In most cases, ash is disposed of in landfills. These wastes contain barium, cadmium, selenium, etc. (Burt et al., 2013). Certainly, those groups that live close to the plants and landfills are most affected, and they bear the burden of social cost. However, the research on the influence of coal ash on human health is limited (Kravchenko \& Lyerly, 2018).

The external cost of these negative effects is hard to evaluate for several reasons, including its ephemeral nature and presence of large uncertainties (Carriazo, 2016). However, there have been attempts to aggregate the externalities of electricity generation. By conducting epidemiological studies, associations between exposure to pollutants and the manifestation of health problems could be established. Robert Phalen, a Professor of Medicine in the Center for Occupational and Environmental Health at the University of California, Irvine, indicates that about 150 periodical scientific journals deal with issues within epidemiology and toxicology (Phalen, 2013). Results of this field of research show considerable evidence that these pollutants entail public health costs comparable to the costs of global warming from greenhouse gas emissions (Rabl \& Spadaro, 2006). Conducted studies have suggested that up to $95 \%$ of these external costs fall on the population's adverse health effects (ibid).

Another recent study conducted jointly by the Boston University School of Public Health and the Institute for the Environment examined how changes in insulation will lead to lower emissions. According to the results of the study, it turned out that decreases in electricity generation due to increased residential insulation for all single-family houses 
across the continental US in 2013 would lead to annual reductions of 80 million tons of $\mathrm{CO}_{2}, 68000$ tons of $\mathrm{NO}_{\mathrm{x}}$ and 120000 tons of $\mathrm{SO}_{2}$ (Levy et al., 2016). The same study concluded that the annual U.S. monetized health benefits related to improved insulation are worth $\$ 2.9$ billion. The researchers conducted the study omitted impacts of $\mathrm{PM}_{2.5}$.

Researchers of the School of Public Health at the University of Illinois at Chicago (UIC) specified that the most pronounced effects on the respiratory system come from three categories of pollutants (Burt et al., 2013): PM, SO2 and nitrogen oxides. The American Lung Association also pinpoints that PM and ozone pollution dominate in the U.S. (Paul et al., 2019). A recent study conducted by the American Council for an Energy-Efficient Economy (ACEEE) found that reducing energy consumption through efficiency by just $15 \%$ for one year would save six lives every day, prevent nearly 30,000 asthma attacks each year and save Americans up to $\$ 20$ billion in avoided health impacts (Hayes \& Kubes, 2018).

\subsection{Particulate Matter}

Despite such a wide variety of conditions that affect the presence of air contaminants, epidemiologic studies have indicated a statistically significant association between increases in daily mortality and the concentrations of particles less than 2.5 and $10 \mu \mathrm{m}$ (Adams et al., 2015). If inhaled deeply coupled with high concentrations or long-term exposure, it can result in serious health impacts, including ischemic heart disease (IHD) (Krewski et al., 2009), and adverse birth outcomes (Ha et al., 2017).

The Krewski study (2009), who conducted epidemiologic study with data collected over 18 years, and called for additional support for other population-based studies aimed to justify the hypothesis of detrimental effects $\mathrm{PM}_{2.5}$ has on human health. The $\mathrm{PM}_{2.5}$ subgroup of particles is of particular concern among researchers since it has been revealed that ever a short-term (a few hours to weeks) can trigger a cardiovascular disease (Brook et al., 2010). 
An Integrated Epidemiological and Toxicologic Studies of the Health Effects of Particle Matter Components funded under the Health Effects Institute's National Particle Component Toxicity (NPACT) Initiative concluded that secondary sulfate has a negative effect on health. Secondary sulfate occurs during oxidation of gaseous SO2 emitted from fossil-fuel combustion sources, and it was most consistently associated with both shortand long-term adverse effects of $\mathrm{PM}_{2.5}$ exposure (Lippmann et al., 2013). However, the authors also concluded that the PM blend's multi-component composition is one of the complicating factors that affect the evaluation of the impact on human health (ibid).

\subsection{Nitrogen Oxides}

Exposure to higher levels of NO2 can decrease efficacy of lung function and increase bronchial reactivity. The results of the 2001 study show that $\mathrm{NO}_{2}$ can exacerbate respiratory diseases such as asthma by triggering the release of inflammatory mediators from the epithelial cells of the bronchi, and that cells of asthmatic people may be more susceptible to hostile effects of these pollutants (Bayram et al., 2001). In addition, the results of a study suggest that concurrent exposure to PM and nitrogen oxides while breathing has a synergistic effect (Huang et al. , 2012). A different study demonstrated that exposure of thirty healthy, nonsmoking participants with no history of respiratory disease inhaled air containing two ppm $\mathrm{NO}_{2}$ in an environmental chamber. As a result, the impact of exposure to $\mathrm{NO}_{2}$ entailed a neutrophilic airway inflammation (Blomberg et al., 1997). In this way, not only people with asthma, as well as children and the elderly who are generally at greater risk, but healthy people may suffer from a slight increase in concentration.

\subsection{Ozone}

Johns Hopkins Bloomberg School of Public Health and Yale University researchers ran a meta-analysis of 144 effect estimates from 39 time-series studies that revealed an association between short-term changes in ozone and mortality (Bell et al., 2005). According to the results of the study, a single 10-ppb increase during the day increases the 
chances of premature death by $0.87 \%$. For comparison, we can draw an analogy that one ppb is proportional to one second in nearly 32 years (Satterfield, 2004). Ozone can cause immediate breathing problems since it imposes a load on the respiratory system in two ways: due to high oxidizing properties, or indirectly provoking airway inflammation (Mudway et al., 1999). The body's response can be coughing, sneezing, shortness of breath, increased susceptibility to respiratory infections, and asthma attacks.

\subsection{Sulfur Dioxide}

Scientific evidence demonstrates that there is a causality between short-term $\mathrm{SO}_{2}$ exposure and respiratory morbidity, especially in individuals with asthma (Sheppard et al., 1980). $\mathrm{SO} 2$, like ozone, also causes inflammatory processes in the airways that cause complications in individuals with asthma. For example, if the short-term exposure to doses exceeding five ppm caused small but significant impairments in breathing function in ordinary people. Similar effects occurred in people with chronic respiratory diseases with an increase of even one ppm (Sheppard, 1988). It was estimated by WHO that there were about 300 million people worldwide with asthma in 2005, and the disease put to death approximately 250,000 people annually (WHO, 2007). Observations trace the trend that a high rate of asthma is inherent in industrial countries. Expecting that many less developed countries will follow suit, it is likely that the number of people with asthma could reach 400 million by 2025 (Reno et al., 2015). 


\section{Energy Efficiency}

As demonstrated, a growing body of research has already established a connection between emissions from fossil fuels - in particular from high sulfur coal - and effects on human health. Often, information from various sources illuminates a certain part of the equation, depending on who conducts the study. However, there is a moderate number of resources on how energy efficiency programs and standards contribute to the mitigation of the impacts. Therefore, this section highlights how energy-efficiency programs can mitigate the various impacts of coal-fired power plants.

\subsection{Benefits}

Richard A. Muller, a professor of physics at the University of California, Berkeley, admits in his book that energy-efficiency is a valuable tool in combating modern challenges (Muller, 2013). Implementing EE programs can bring the following benefits:

Environmental gains: A huge chunk of today's electricity generation in the United States comes from the electricity generating units (EGU), which either incinerate carbon-based fuels like coal, natural gas, and biofuels or from plants that use nuclear fuel to heat water and produce steam. Steam generated from fuel combustion spins a turbine to produce electricity, but burning also releases greenhouse gas emissions that contribute to climate change. Through the energy efficiency improvements of residential and commercial buildings, there is less need for electricity and thus less burning. Decreased need for electricity benefits the environment by reducing carbon dioxide emissions. Fourth National Climate Assessment report released in 2018 admits that

"In 2016, U.S. emissions were at their lowest levels since 1994. Power sector emissions were 25\% below 2005 levels in 2916, the largest emissions reduction for a sector of the American economy over this time" (Wuebbles et al., 2017). 
Although reduction of power sector emissions was achieved through the implementation of different approaches, improved energy efficiency standards and programs contributed as much as other structural changes.

Economic benefits. The economic benefits of energy efficiency are not only limited by lowering energy bills for consumers. Energy efficiency also contributes to economic development and job creation. The ability of any activity or program to create jobs is often used as a powerful argument in justifying the need for investment. Energy-efficiency investments initiate more jobs than a comparable investment in either the energy sector or economy on average. For instance, a $\$ 1$ million investment to push on building efficiency will initially support approximately 20 jobs throughout the economy (ACEEE, n.d.). In addition to the instantaneous job creation benefits brought about by efficiency program investments, there are also jobs created as results from the consumer savings on energy bills. When a business or household lowers their energy costs, they are then able to spend that money elsewhere in the economy, resulting in additional jobs (ibid).

Whereas that the unit of energy saved is more than the unit of energy produced, since the transmission and distribution of the unit are inevitably associated with a considerable loss, any decrease in the demand side contributes to less pressure on the system. Demand-side management likewise improves the operation of the existing infrastructure.

Social benefits. Many people perceive air pollution as something related to the outer environment. However, indoor air is much more polluted than outside air. Energy-efficient technologies help increase both outdoor and indoor air quality. The U.S. Environmental Protection Agency (EPA) and the U.S. Department of Energy (DOE) emphasize the importance of improving indoor air quality. People spend approximately $90 \%$ of their time inside a home, office, or other types of dwelling, where the concentrations of some pollutants are often two to five times higher than typical outdoor concentrations (EPA, 1989). A report by the American Lung Association declares that currently, more than 125 million people - or about $40 \%$ of Americans - were more or less exposed to harmful levels of pollutants, much of which released from power plants (Paul et al., 2019). Children, 
pregnant women, seniors, and people with respiratory diseases are the most vulnerable to this type of pollution.

These high rates of indoor air pollutants are associated with the low quality of building insulation, poor ventilation, and the use of synthetic building materials and furnishings. This problem is acquiring a socio-economic background as income-sensitive people live in dwellings with worse conditions.

On the other hand, evaluating the benefits of these programs is a difficult task since the quantitative component is poorly developed for many benefits, which would fully reflect the situation. Looking back, implemented policies have numerous obvious benefits. Still, some state energy efficiency policies have encountered initial confrontation because the benefits have not been fully measured or considered when comparing costs and benefits that often lead to decision making.

Concluding, these benefits consist of the following categories:

- $\quad$ lower fuel and electricity costs;

- $\quad$ increase in grid reliability

- $\quad$ more job opportunities

- $\quad$ better air quality

- $\quad$ improvement in public health

When evaluating the cost-effectiveness of these programs, savings in electricity and other direct energy benefits may be included. However, according to a recent study conducted by the ACEEE (Hayes \& Kubes, 2018), there is no reputable standard of evidence or criteria used to identify the relationship between program involvement and health results. Studies conducted in an academic environment use various approaches and tools that sometimes produce distinctive results from each other. However, based on the volume of literature studied, it follows that incorporating the monetary value of health benefits 
significantly shortens the return on investment spent on the implementation of energy efficiency measures.

\subsection{Limitations}

From an economic standpoint, even though that energy-efficient practices are usually considered as measures suggesting a decrease in energy consumption, in fact, in many cases, the so-called rebound effect, or Jevons paradox, is observed (cite for Jevons Paradox). This effect is due to the fact that technological advances that allow us to perform more while consuming less can ultimately increase consumption. A classic example is the increased efficiency of cars, which allowed people to use cars more often. Decreased marginal costs for energy services may induce an increase in energy demand (Gillingham et al., 2009). Overall, energy savings related to new, more energy-efficient technologies, particularly for lightning, were likely to bring in significant increases in energy consumption. Thus, substantial percentages of energy savings will be lost to increased energy consumption. Further, efficiency gains are limited in their geographical impacts; since administrative divisions and borders do not apply to the migration of atmospheric emissions, a reduction of the latter in one place does not guarantee an improvement in local air quality unless a joint approach is taken between countries, etc.

\subsection{Illinois Energy-Efficiency Portfolio Standard for Electricity Generation}

The Illinois Power Agency Act (IPAA) that was enacted in August of 2007 shaped energy efficiency and demand response programs in Illinois. Under the requirements of the Act, electric utilities with or more than one hundred thousand customers have need to demonstrate annual savings reduction. The goal was to provide a gradual annual reduction in electricity sales equal to $0.2 \%$ of the previous year's electricity sales from 2008-2009 to 2016. By 2016, a gradual annual increase should have reached a $2 \%$ level. The level of savings remains at this value for all subsequent years. Utilities are obliged to file an energy efficiency and demand response plans with the Illinois Commerce Commission (ICC) every three years. Typically, energy savings goals are achieved through end-use efficiency 
programs. The 2016 Future Energy Jobs Bill (SB2814) required both Ameren and ComEd to allocate \$25 million every year through 2030 to income-eligible efficiency programs. 


\section{Methodology}

The AVoided Emissions and GeneRation Tool (AVERT), created by the EPA, is an open access software. The CO-Benefits Risk Assessment Health Impacts Screening and Mapping (COBRA) is a second tool used in this study. During the summer internship, AVERT and COBRA were considered as main tools in evaluating the impacts of coal power plants' emissions on public health. These programs are recommended by the agency for assessing emissions, which may be carried out by various individuals. AVERT and COBRA were used to carry out the analysis of the monetized public health benefits of uniform energy efficiency programs and projects. In this case, the total amount of electricity reduced throughout 2019 is distributed equally over the year. The analysis is premised on two scenarios, where $1.8 \%$ and $2 \%$ reductions of annual electricity generation are achieved for 2019. AVERT estimates emission reductions from fossil-fuel generating units. For the purposes of this analysis, annual electricity savings of two scenarios is overwhelmingly comprised of coal power plants. The assumption will be explained more detailed in the section below.

The following steps were taken to complete the analysis:

1. Determine the percentage reduction that is achieved through the use of different EE programs, projects, etc.

2. Estimate changes in emissions of criteria pollutants due to the reduction of fossil-based electricity generation.

3. Estimate adjustments in ambient concentrations of primary $\mathrm{PM}_{2.5}$ and precursors of secondary $\mathrm{PM}_{2.5}$.

4. Evaluate changes in public health impacts caused by modified ambient concentrations of $\mathrm{PM}_{2.5}$.

5. Outlay the monetary value of changes in public health impacts.

Figure. 7.1 depicts the general flow of the analysis. 


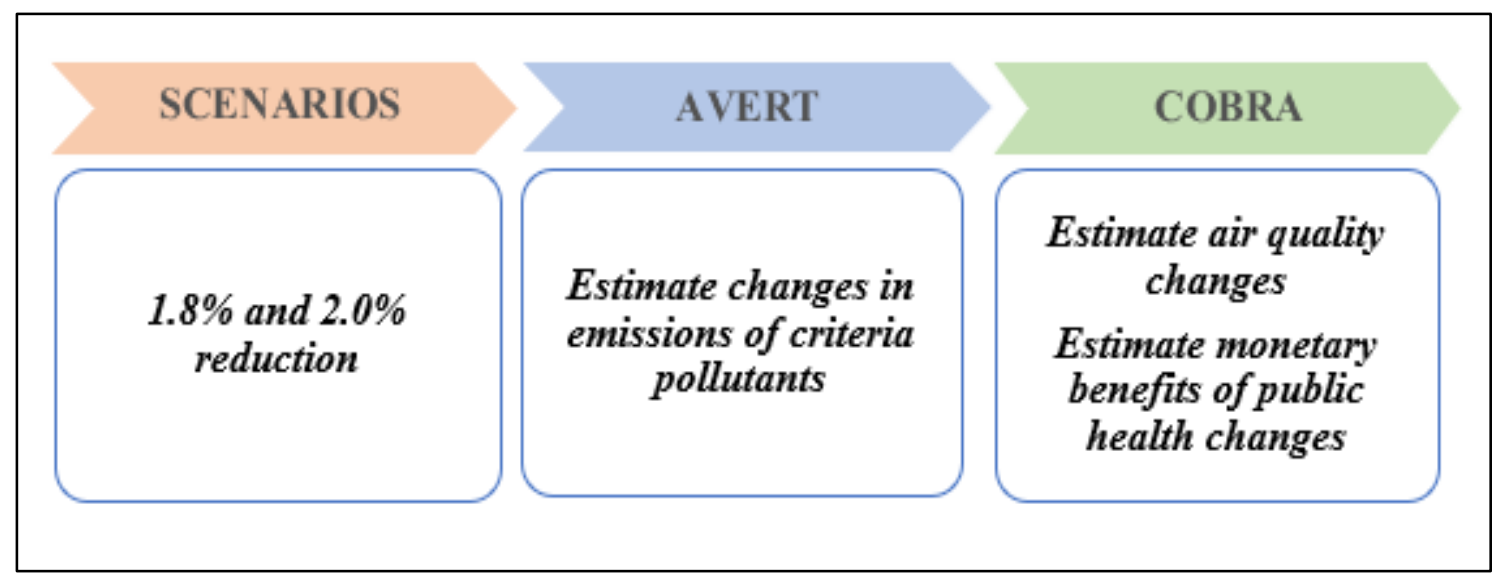

Figure 7.1 Analysis flow (Source: Figure by author).

\subsection{Scenarios}

The $1.8 \%$ and $2 \%$ reduction in fossil fuel generation scenarios, as mentioned earlier, were considered. Illinois has already reached $2.3 \mathrm{GWh}$ of net incremental savings as of 2018. In percentage terms, this indicator reached $1.66 \%$ compared to the amount of electricity generated in 2017 (Berg et al., 2019). Given the current trend, the achievement of $1.8 \%$ net energy efficiency savings is very likely. Thereby, the option of achieving $1.8 \%$ is considered as an expected outcome for 2019. The second scenario that is viewed as optimistic involves reaching a two-percentage point. Prediction of making an optimistic scenario has been introduced to compare results.

\subsection{AVERT}

The goal of the study is to model the effect of implementing EE measures on the reduction of criteria pollutants and further economic evaluation of the benefits. Several tools can be used for modeling. Some of them are basic, for example, when non-baseload emissions rates are multiplied by the avoided generation. EPA's Emissions and Generation Resource Integrated Database (eGRID) is based on this approach. Non-baseload emissions rates can be used for conducting rough estimates of displaced emissions due to RE/EE projects. The main drawback of these modeling tools is that input changes impact all plants. Other tools allow for a higher level of analysis complexity, generally yielding more precise results. 
However, these tools often have licensing costs and may require specialized technical training.

In this study, AVERT was selected for modeling. Depending on the tasks and scope, this tool can be used for basic- and intermediate-level analyses. AVERT is publicly available and can be downloaded from the EPA's website. It has a simple user interface designed to meet the needs of state air quality planners, public utility commission personnel, and other interested stakeholders. Given its user-friendly interface, non-experts can use AVERT to evaluate emissions for different jurisdictional levels (county, state, region). The tool is designed to use accessible public data reported to EPA's Clean Air Markets Division by EGU. EPA periodically releases updates for the data on its website. A release for the preceding year usually happens by the end of the second quarter of the current year.

AVERT estimates avoided emissions for criteria pollutants from EGUs attributable to the implementation of RE and EE measures. It utilizes statistical algorithms (Monte Carlo simulations), which take into account the behavioral characteristics of each EGU. New RE and EE resources typically reduce energy consumption from fossil fuels, and as a consequence, it eliminates the need to dispatch electricity from existing EGU over a short time. In the long run, this can help get rid of the need to build new units. The generation which is not produced because of the substitution is the avoided generation. Relying on the historical hourly generation and emissions rates of nearly every US EGU, AVERT predicts future generation behaviors with additional implemented EE or RE. The program is designed to review the results of marginal load changes.

Structurally AVERT is divided into two key modules: the main module and statistical module with a future-year scenario template. The main module estimates the displaced emissions expected to result in from the intervention of a EE or RE program in reference to a base-year or future-year scenario. The program currently maintains historical data from 2007 through 2018 as base years. A future-year scenario is used when alterations to the existing system are expected. As of early 2020, the most recent scenario is for 2018. Users can remove or add an EGU, modify emissions characteristics in the template. The next step 
is processing the modified template in the Statistical module. The Statistical Module contains MATLAB-formatted flat data files of EGUs' hourly generation and emissions. It uses the MATLAB Compiler Runtime (MCR) that enables the user to run applications compiled within MATLAB. As the next step in preparing data that can be used in the Main module, it is required to run Monte Carlo simulations. Monte Carlo simulations are employed to model the probability of different outcomes in highly randomized processes that cannot easily be predicted. EPA's user guide recommends running 1000 iterations as a default number. The base datasets provided by EPA are outcomes of 5000 Monte Carlo runs.

For conducting the study, the regional data files for 2018 were used. The data are prepared by EPA for further use in the Main Module. According to the EPA's delimitation of the regions, electricity generation in Illinois is divided between Great Lakes/Mid-Atlantic and Upper Midwest regions (Fig. 7.2). These two regions are among the ten major areas that are aggregates of EPA's eGRID subregions. The boundaries resemble the borders used by the North American Electric Reliability Corporation.

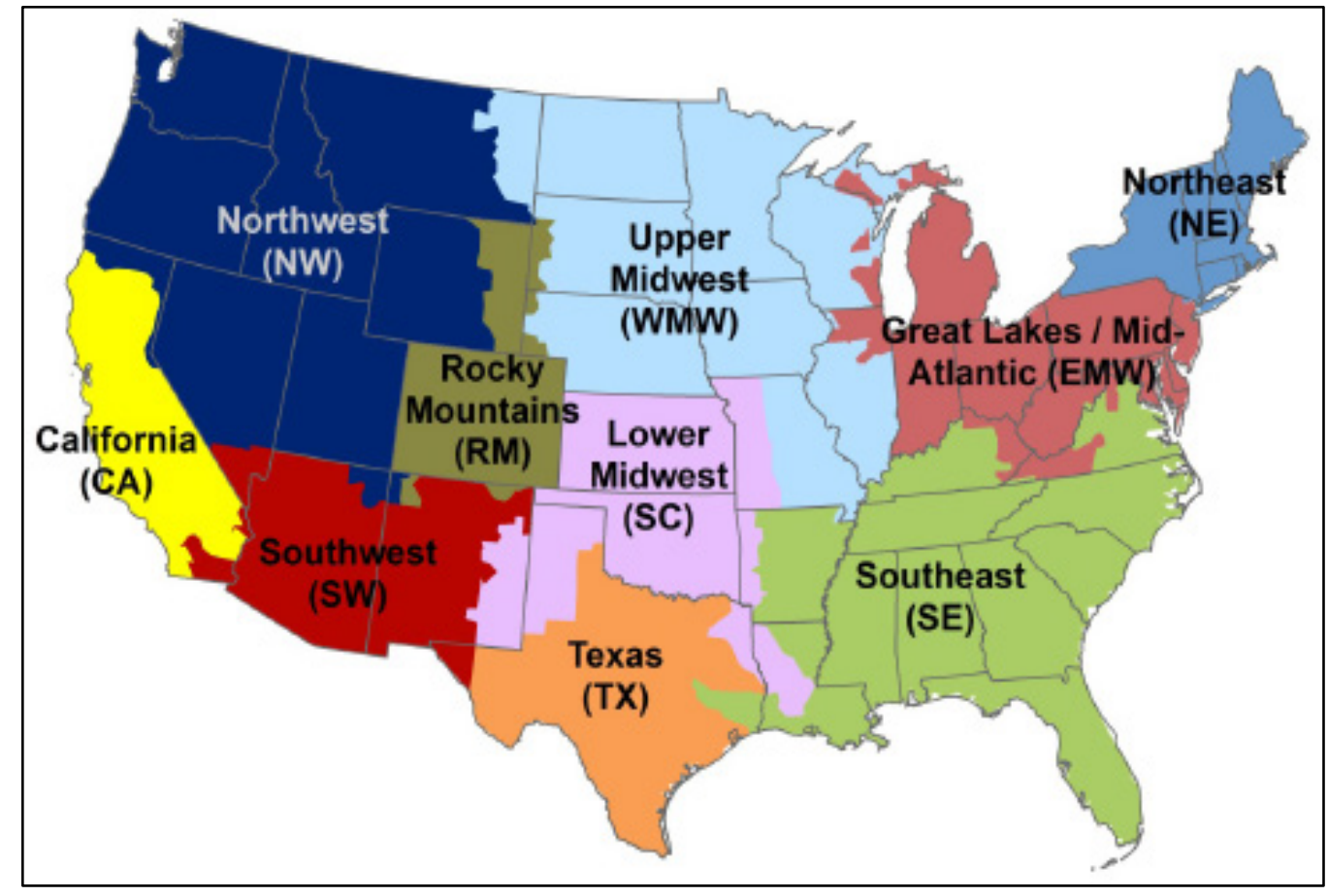

Figure 7.2 Map of AVERT regions. (Source: EPA's AVERT Tutorial). 


\subsection{COBRA}

COBRA was designed to use primarily as a screening tool. It offers a preliminary evaluation of the impact of changes in ambient $\mathrm{PM}_{2.5}$ air pollution concentrations. Further, internal algorithms (built-in emissions inventories, an air quality model) interpret it into the health effects impacts and monetizes these impacts as a final product. The basic option allows an operator to create new scenarios by specifying increases or reductions to the baseline emissions estimates for the analysis year. It gives a researcher a first-order approximation of the benefits. Results include changes in the ambient PM2.5 concentrations and associated health endpoints. The analysis flow is depicted in Figure 7.3 below.

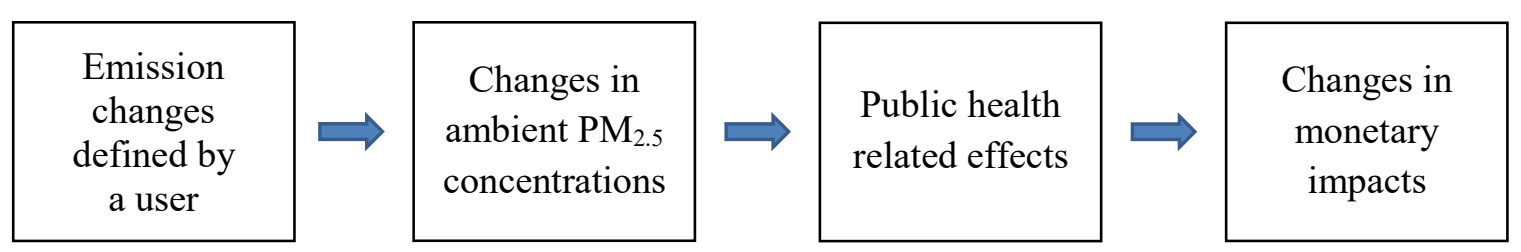

Figure 7.3 COBRA's modeling (Source: Figure by author)

For the first step, data obtained from AVERT was entered to complete the first step for emission changes. Ultimately, a comparison of $1.8 \%$ and $2.0 \%$ scenarios is made that weighs the monetary results. COBRA focuses on health impacts by considering only primary and secondary $\mathrm{PM}_{2.5}$ pollution. Levy (2002) admits that this type acts as a more harmful agent for mortality and morbidity rather than other gaseous compounds.

COBRA employs a relatively simple air quality model, which brings some degree of uncertainty. Given this, the researcher or policy analyst conducting the assessment using COBRA must be aware of the limitations. As it was mentioned earlier, the tool gives screening capabilities. Some of the barriers that should be considered when using COBRA are listed below. 


\section{Limitations}

Being an intermediate tool, AVERT has its limitations. EPA denotes that the AVERT Main module cannot fully capture long-term estimations (more than five-year) when there are critical adjustments to the electrical grid (new power plants or transmission resources). Another limitation that the tool also cannot assess significant changes of an EGU fleet. Unlike other electricity system simulation dispatch models, AVERT neglects in its analysis such parameters as operating costs to estimate how and when an EGU is dispatched to meet load requirements. As a result, there are important characteristics that AVERT omits: changing fuel or emissions prices, relationships between EGUs, EGU maintenance downtime, and ramp-rates (EPA, 2019b).

EPA recommends using COBRA as a screening tool because of the limited studies that aimed to validate the results obtained by using the S-R Matrix. The Matrix does not have full comprehension of all the complex interactions between air pollutants in the atmosphere. The developers adjusted an initial probabilistic method used in COBRA to ensure consistent distribution of contaminants.

\section{Assumptions}

As noted in chapter two, nuclear power plants are the dominant source of electricity in Illinois. Generally, nuclear power plants are operated as baseload units and located in the lower end of the dispatch curve for both economic and technical reasons (EIA, 2012). Coal and natural gas EGUs will likely act as marginal power plants responding to the peak demand (Fig. 7.4). Considering this and the fact that natural gas accounts for $9 \%$ of the state's electricity generation, it is assumed here that displaced emissions due to implemented EE measures will be accounted toward coal-based EGU (Fig 7.5). 


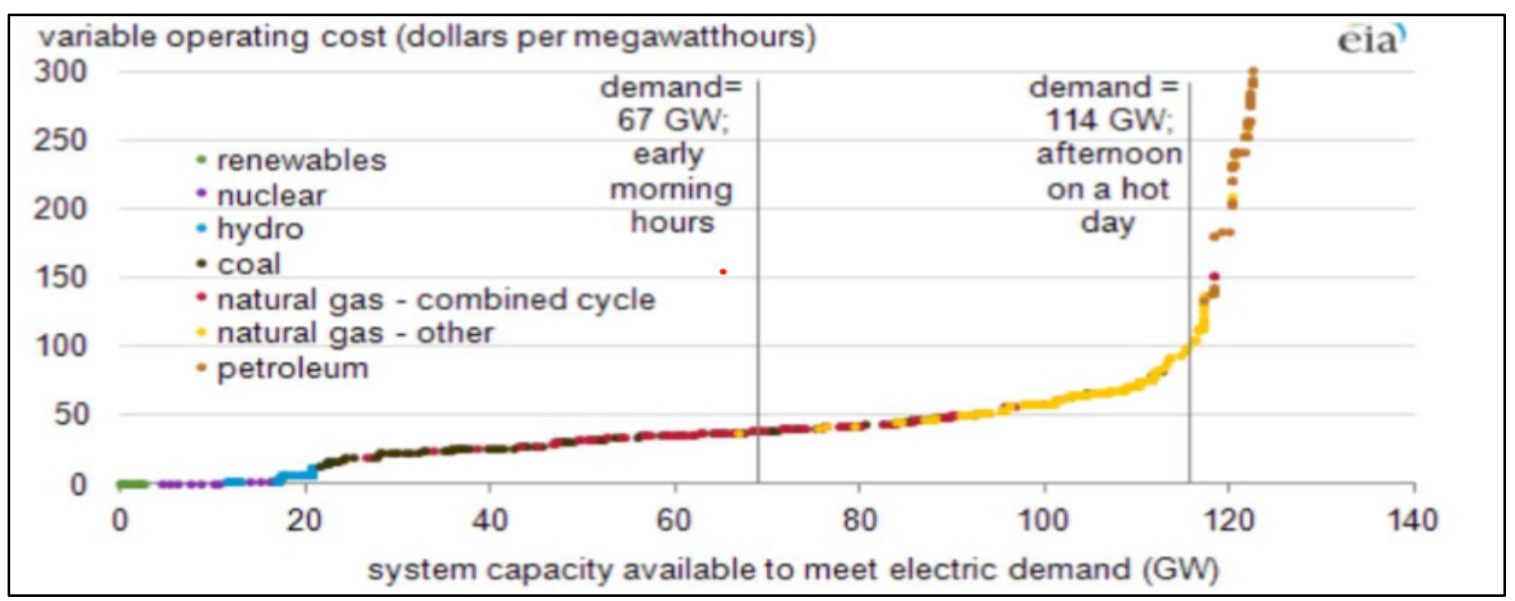

Figure 7.4 Hypothetical dispatch curve for summer 2011. (Source: The U.S. EIA Electric generator dispatch)

Based on the limitations noted above, it is assumed that fuel prices, emission allowances, pollution control retrofits remained unchanged in the analysis period.

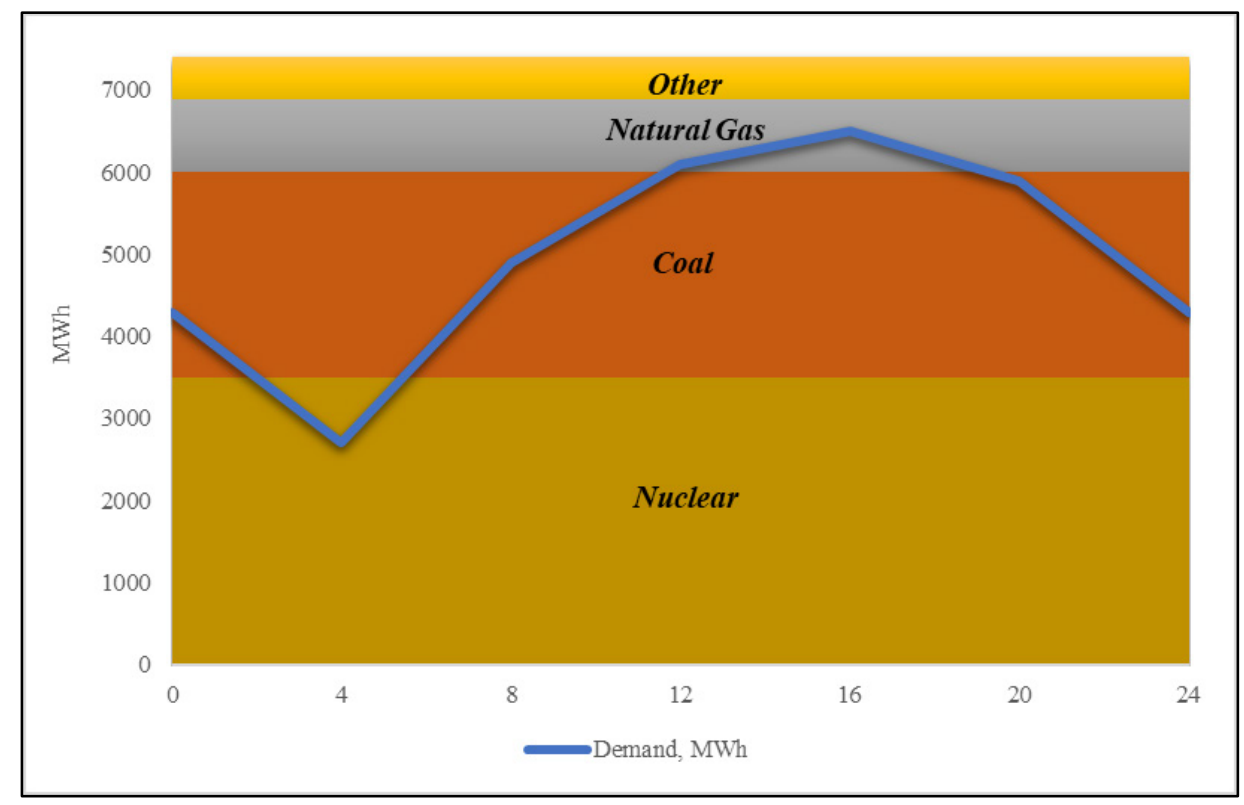

Figure 7.5 Hypothetical daily electric load curve (Source: Figure by author).

Another assumption inherent to AVERT is that regions are autonomous units, and they do not export or import electricity from one another. Thus, displaced emissions are limited within the region's boundaries. The next assumption is that there have not been the initiations of new power plants and the retirements of existing ones during 2019. Another 
assumption relates to the process of evaluating the economic performance of emission reductions.

COBRA holds detailed emissions estimates for the 2017 and 2025 baseline years. Emissions reduction estimates gained through running analysis in the AVERT Main module and then compared with COBRA's 2017 baseline data. It is assumed that critical characteristics, such as population and incidence rates are constant from 2017 to 2019 . A minor gap between these years conditionally allows running COBRA with a projected emissions inventory for 2019 and the default 2017. Another essential factor requiring assumption in assessing the consequences is that primary emissions from a county are evenly distributed over the county's area. Thus, emissions impact the source county itself. 


\subsection{Results}

Compliance with $1.8 \%$ annual savings would be associated with annual reductions of 1.7 million tons of $\mathrm{CO}_{2}, 827$ tons of $\mathrm{NO}_{x}$, and 1042 tons of $\mathrm{SO}_{2}$. Concerning $\mathrm{PM}_{2.5}$, it will result in a decrease of 80 tons. Accordingly, achieving 2.0\% savings will cause reductions of 1.9 million tons of $\mathrm{CO}_{2}, 917$ tons of $\mathrm{NO}_{x}$, and 1160 tons of $\mathrm{SO}_{2}$. As for $\mathrm{PM}_{2.5}$, there will be 88 tons reduced. Tables 7.1 and 7.2 illustrate how indicators change over the year for both scenarios.

Table 7.1 Monthly displaced volumes for $1.8 \%$ annual saving

\begin{tabular}{|c|c|c|c|c|c|}
\hline Month & $\begin{array}{c}\text { Displaced } \\
\text { Generation } \\
(\mathbf{M W h})\end{array}$ & $\begin{array}{c}\text { Displaced } \\
\mathrm{SO}_{2} \\
(\mathrm{lbs})\end{array}$ & $\begin{array}{c}\text { Displaced } \\
\text { NO }_{x} \\
\text { (lbs) }\end{array}$ & $\begin{array}{c}\text { Displaced } \\
\text { PM}_{2.5} \\
\text { (lbs) }\end{array}$ & $\begin{array}{c}\text { Displaced } \\
\mathrm{CO}_{2} \\
\text { (tons) }\end{array}$ \\
\hline Jan & 202,650 & 206,460 & 164,540 & 17,300 & 165,790 \\
\hline Feb & 138,890 & 164,950 & 105,060 & 9,890 & 117,880 \\
\hline Mar & 131,910 & 165,940 & 98,330 & 9,270 & 117,750 \\
\hline Apr & 104,250 & 124,840 & 74,880 & 6,850 & 91,870 \\
\hline May & 142,270 & 160,440 & 117,250 & 10,110 & 119,860 \\
\hline Jun & 182,200 & 180,490 & 149,940 & 15,170 & 149,580 \\
\hline Jul & 242,460 & 188,460 & 231,820 & 22,490 & 194,580 \\
\hline Aug & 245,930 & 197,940 & 237,980 & 22,710 & 198,040 \\
\hline Sep & 179,750 & 174,900 & 150,090 & 15,110 & 147,290 \\
\hline Oct & 132,600 & 147,340 & 96,830 & 8,980 & 113,910 \\
\hline Nov & 141,740 & 180,510 & 109,380 & 10,230 & 122,830 \\
\hline Dec & 150,600 & 191,230 & 117,320 & 11,180 & 131,440 \\
\hline
\end{tabular}


Table 7.2 Monthly displaced volumes for $2.0 \%$ annual saving

\begin{tabular}{|c|c|c|c|c|c|}
\hline Month & $\begin{array}{c}\text { Displaced } \\
\text { Generation } \\
(\mathbf{M W h})\end{array}$ & $\begin{array}{c}\text { Displaced } \\
\mathrm{SO}_{2} \\
\text { (lbs) }\end{array}$ & $\begin{array}{c}\text { Displaced } \\
\text { NO }_{x} \\
\text { (lbs) }\end{array}$ & $\begin{array}{c}\text { Displaced } \\
\text { PM}_{2.5} \\
\text { (lbs) }\end{array}$ & $\begin{array}{c}\text { Displaced } \\
\mathrm{CO}_{2} \\
\text { (tons) }\end{array}$ \\
\hline Jan & 225,280 & 230,170 & 182,920 & 19,210 & 184,570 \\
\hline Feb & 153,660 & 182,670 & 116,240 & 10,900 & 130,380 \\
\hline Mar & 146,300 & 184,430 & 109,120 & 10,240 & 130,630 \\
\hline Apr & 117,050 & 139,190 & 83,700 & 7,720 & 102,820 \\
\hline May & 158,010 & 178,240 & 129,350 & 11,280 & 133,170 \\
\hline Jun & 202,540 & 201,820 & 166,520 & 16,820 & 166,550 \\
\hline Jul & 269,370 & 210,180 & 256,910 & 25,000 & 216,260 \\
\hline Aug & 272,940 & 220,640 & 262,870 & 25,200 & 220,010 \\
\hline Sep & 199,470 & 193,760 & 167,180 & 16,710 & 163,620 \\
\hline Oct & 148,050 & 164,390 & 107,910 & 10,060 & 127,250 \\
\hline Nov & 156,880 & 201,170 & 121,240 & 11,330 & 136,170 \\
\hline Dec & 167,610 & 212,450 & 129,830 & 12,460 & 146,030 \\
\hline
\end{tabular}


Figure 7.6 depicts how changes in electricity generation and emission reductions of the four types of pollutants are distributed.

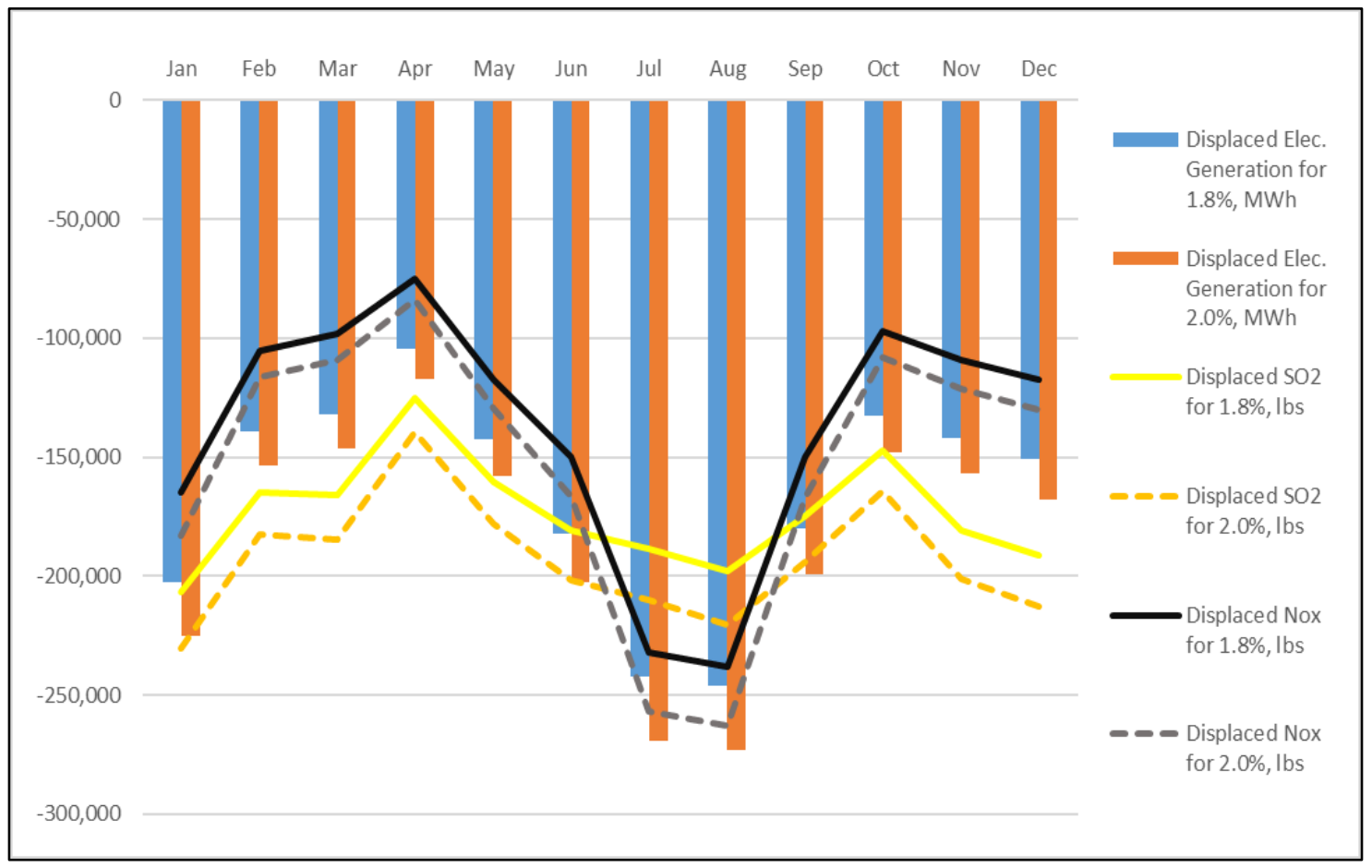

Figure 7.6 Displaced Electricity Generation (MWh) for 2019

A peak of decline occurs in the summer months, due to the nature of electricity consumption. As noted in Chapter 2, about 19\% of electricity is used for space heating; most of the heating in Illinois comes from natural gas. Accordingly, during the summer months, there is an increase in consumption for air conditioning. This increase explains the larger values for the summer months.

In total, Table 7.3 displays the AVERT model's estimates of the annual reduction in $\mathrm{SO}_{2}$, $\mathrm{NO}_{\mathrm{X}}, \mathrm{PM}_{2.5}$, and $\mathrm{CO}_{2}$ emissions that would result from Illinois' compliance with $1.8 \%$ and $2.0 \%$ yearly reduction of electricity generation. In the first case, achieving $1.8 \%$ annual savings will reduce electricity generation almost by 2,000 GWh. In comparison, $2.0 \%$ of annual reduction will be accompanied by $2,200 \mathrm{GWh}$, which is $11 \%$ higher than in the first scenario. Similar ratios are maintained in other indicators. 
Table 7.3 Annual displaced volumes and percent change for two scenarios

\begin{tabular}{lrrr}
\hline & $\begin{array}{r}\mathbf{1 . 8 \%} \text { annual } \\
\text { saving }\end{array}$ & $\begin{array}{r}\mathbf{2 . 0 \%} \text { annual } \\
\text { saving }\end{array}$ & \% change \\
\hline Displaced Generation (GWh) & $1,995.3$ & $2,217.2$ & $11.1 \%$ \\
Displaced $\mathrm{SO}_{2}$ (tons) & $1,041.8$ & $1,159.6$ & $11.3 \%$ \\
Displaced $\mathrm{NO}_{x}$ (tons) & 826.7 & 916.9 & $10.9 \%$ \\
Displaced $\mathrm{PM}_{2.5}$ (tons) & 79.7 & 88.5 & $11.1 \%$ \\
Displaced $\mathrm{CO}_{2}$ (tons) & $1,670,820$ & $1,857,460$ & $11.2 \%$ \\
\hline
\end{tabular}

The state's total monetized health co-benefits in the implementation year range between \$12.6 and \$28.3 million for two scenarios in 2017 dollars (Table 7.4). Most of this value is associated with avoided mortality due to decreases in $\mathrm{PM}_{2.5}$; the remainder is resulting from effects on morbidity. EPA applies the value of statistical life (VSL) to calculate estimates of mortality benefits. The agency discounts the value of premature mortality by using rates of $3 \%$ and $7 \%$ for future years. The VSL has been widely adopted to measure the benefits. The results are shown in Table 7.4.

Table 7.4 Total Health Benefits

\begin{tabular}{ccrr}
\hline $\begin{array}{c}\text { Annual } \\
\text { saving, \% }\end{array}$ & $\begin{array}{c}\text { Discount } \\
\text { Rate, \% }\end{array}$ & $\begin{array}{r}\text { Total Health Benefits } \\
\text { (low estimate), 2017\$ }\end{array}$ & $\begin{array}{c}\text { Total Health Benefits } \\
\text { (high estimate), 2017\$ }\end{array}$ \\
\hline \multirow{2}{*}{1.8} & 3 & $12,644,105.1$ & $28,584,972.9$ \\
& 7 & $11,284,860.5$ & $25,500,610.9$ \\
2.0 & 3 & $14,053,865.1$ & $31,772,032.1$ \\
& 7 & $12,543,070.8$ & $28,343,781.4$ \\
\hline
\end{tabular}

Table 7.4 gives a low estimate and a high estimate. These estimates are based on two approaches. The lowest rating is based on the lowest measured level equal to $5.8 \mu \mathrm{g} / \mathrm{m}^{3}$, and one standard deviation below the mean is $11.0 \mu \mathrm{g} / \mathrm{m}^{3}$. For the high estimate, the lowest measured level is $8 \mu \mathrm{g} / \mathrm{m}^{3}$. Unfortunately, there was no data for one standard deviation below the mean (EPA, 2018). 
The following table compares the difference in benefits that can be obtained by the following two scenarios. Consequently, the difference of $0.2 \%$ between $1.8 \%$ and $2.0 \%$ brings an additional $\$ 1.2$ to $\$ 3.1$ million depending on the level of estimate and discount rate (Table 7.5).

Table 7.5 Difference in health benefits between $1.8 \%$ and $2.0 \%$ annual savings

\begin{tabular}{|c|c|c|}
\hline \multirow{2}{*}{ Discount Rate, \% } & \multicolumn{2}{|c|}{$0.2 \%$ difference in annual saving results in } \\
\hline & Low estimate, $2017 \$$ & $\begin{array}{c}\text { High estimate, } \\
2017 \$\end{array}$ \\
\hline 3 & $1,409,760.0$ & $3,187,059.2$ \\
\hline 7 & $1,258,210.3$ & $2,843,170.5$ \\
\hline
\end{tabular}




\section{Conclusion}

During the execution of the summer internship project, it was planned to use AVERT and COBRA tools developed by EPA to quantify public health damage from airborne emissions. Using these tools allowed us to measure the harm caused by air emissions from coal based power plants in Illinois. It was also helped to understand how the intervention of energy efficient measures is affecting fossil-fuel generators. While the results of the study provide only benefits obtained from decreasing PM2.5, it can be inferred that reduction in coal fired electricity generation can entail more substantial benefits.

For example, the monetary value obtained in the calculation of the health impacts of $\mathrm{PM}_{2.5}$ emission omits carbon dioxide. Even though $\mathrm{CO}_{2}$ does not have a direct negative effect on human health, it has other destructive effects. Thus, including the social cost of carbon into the equation is a significant argument in favor of the introduction of new energy policy instruments and incentives. The overall benefits will be higher if the social cost of carbon is added to the monetary outcomes that were found in this study.

Another finding that was identified after the simulation was that the most significant reduction in emissions occurs during the summer months. It was previously mentioned that the formation of ground ozone occurs in the summer months at high temperatures. This has far-reaching implications for public health. Improving the conditions of Illinois' building stock will mitigate the harmful impacts of ozone coupled with other measures.

Higher consumption in residential buildings compared to states with a similar climate, result in Illinois households spending $2 \%$ more for energy than the U.S. average (EIA, 2009). Implementing EE in both types of buildings will compensate for unnecessary expenditures.

The completed modeling has been designed for future analyses, which can be used by MEAA along with other sources that focus on other EE benefits. As a comparison of the two models showed, even a slight increase of $0.2 \%$ contributes to an additional 1.2-3.2 million US dollars. 
The main tools for achieving a reduction in the harmful effects of air pollutants can be already proven strategies such as building energy codes, appliance standards, and energy efficiency standards. They contribute to saving money, reducing emissions, and securing supply while stimulating the economy. They also may help reduce inequalities in the distribution of existing health and environmental pressures that vulnerable communities face.

Conducting the study has been an influential commitment. During the study, I found out that very complex processes are taking place in the atmosphere, the understanding of which requires further scientific research. Nevertheless, despite a somewhat limited understanding of the complexity, the scientific community was able to establish causality between the level of pollution and the harm to health. Since this problem is universal, the results of the study can be used in my future professional activities, especially in Kazakhstan, a region heavily dependent on coal. 


\section{Reference List}

Adams, K., Greenbaum, D. S. ., \& Shaikh, R. (2015). Particulate matter components, sources, and health: Systematic approaches to testing effects. Journal of the Air \& Waste Management $\quad$ Association, 65(5), 544-558. https://doi.org/10.1080/10962247.2014.1001884

American Council for an Energy-Efficient Economy. (n.d.). How Does Energy Efficiency Create Jobs? Retrieved March 23, 2020, from https:/www.aceee.org/files/pdf/factsheet/ee-job-creation.pdf

Armstrong, M., \& Becerra, M. (2009). Environmental Justice: Mapping Coal Power Plants in Illinois and Chicago A project for the Little Village Environmental Justice Organization.

Bayram, H., Sapsford, R. J., Abdelaziz, M. M., \& Khair, O. A. (2001). Effect of ozone and nitrogen dioxide on the release of proinflammatory mediators from bronchial epithelial cells of nonatopic nonasthmatic subjects and atopic asthmatic patients in vitro. Journal of Allergy and Clinical Immunology, 107(2), 287-294. https://doi.org/10.1067/mai.2001.111141

Bell, M. L., Dominici, F., \& Samet, J. M. (2005). A meta-analysis of time-series studies of ozone and mortality with comparison to the national morbidity, mortality, and air pollution study. Epidemiology (Cambridge, Mass.), 16(4), 436-445. https://doi.org/10.1097/01.ede.0000165817.40152.85

Blomberg, A., Krishna, M. T., Bocchino, V., Biscione, G. L., Shute, J. K., Kelly, F. J., Frew, A. J., Holgate, S. T., \& Sandström, T. (1997). The inflammatory effects of 2 ppm NO2 on the airways of healthy subjects. American Journal of Respiratory and Critical Care Medicine, $\quad 156(2 \quad$ I), $418-424$. https://doi.org/10.1164/ajrccm.156.2.9612042

Brook, R. D., Rajagopalan, S., Pope, C. A., Brook, J. R., Bhatnagar, A., Diez-Roux, A. V., 
Holguin, F., Hong, Y., Luepker, R. V., Mittleman, M. A., Peters, A., Siscovick, D., Smith, S. C., Whitsel, L., \& Kaufman, J. D. (2010). Particulate matter air pollution and cardiovascular disease: An update to the scientific statement from the american heart association. In Circulation (Vol. 121, Issue 21, pp. 2331-2378). https://doi.org/10.1161/CIR.0b013e3181dbece1

Bureau of Economic Analysis, U. S. D. of C. (2019). Current-Dollar Gross Domestic Product (GDP) by State and Region, 2018:Q1-2019:Q3. https://www.bea.gov/system/files/2020-01/qgdpstate0120_0.xlsx

Burt, E., Orris, P., \& Buchanan, S. (2013). Scientific Evidence of Health Effects from Coal Use in Energy Generation Scientific Evidence of Health Effects from Coal Use in Energy Generation Scientific Evidence of Health Effects from Coal Use in Energy Generation. April, 1-18.

Carriazo, F. (2016). Economics and Air Pollution. In Air Quality - Measurement and Modeling. InTech. https://doi.org/10.5772/65256

Clay, K., \& Muller, N. Z. (2019). Recent Increases in Air Pollution: Evidence and Implications for Mortality (No. 26381; Environment and Energy Economics). https://www.nber.org/papers/w26381

Development Centre Studies The World Economy Historical Statistics ... - Maddison Angus - Google Books. (n.d.). Retrieved February 6, 2020, from https://books.google.com/books?hl=en\&lr=\&id=rHJGz3HiJbcC\&oi=fnd\&pg=PA1 $\&$ dq $=$ Maddison + A. + The+world + economy. + Historical + perspectives. + Paris: + OECD ,+2003.\&ots=nKDU23g0vs\&sig=xVLB08NMLU4XGQLhGfp2zq1$85 \mathrm{M} \# \mathrm{v}=$ onepage $\& \mathrm{q}=$ Maddison $\mathrm{A}$. The world economy. Historical perspectives. Paris\%3A OECD\%2C 2003.\&f=false

Dixon, R. K., McGowan, E., Onysko, G., \& Scheer, R. M. (2010). US energy conservation and efficiency policies: Challenges and opportunities. Energy Policy, 38(11), 6398- 
6408. https://doi.org/10.1016/j.enpol.2010.01.038

EIA. (2009). Household Energy Use in Illinois. https://www.eia.gov/consumption/residential/reports/2009/state_briefs/pdf/il.pdf

EIA. (2012). Electric generator dispatch depends on system demand and the relative cost of operation - Today in Energy - U.S. Energy Information Administration (EIA). https://www.eia.gov/todayinenergy/detail.php?id=7590\#

EIA. (2015). EIA's residential energy survey now includes estimates for more than 20 new end uses - Today in Energy - U.S. Energy Information Administration (EIA). https://www.eia.gov/todayinenergy/detail.php?id=36412

EIA. (2018, May). Energy Information Administration (EIA) - About the Residential Energy Consumption Survey (RECS) Table HCl.1 Fuels used and end uses in U.S. homes by housing unit type, 2015. https://www.eia.gov/consumption/residential/data/2015/hc/php/hc10.3.php

EIA. (2019). Illinois - State Energy Profile Overview - U.S. Energy Information Administration (EIA). https://www.eia.gov/state/?sid=IL\#tabs-2

EIA. (2020). Electric Power Monthly. Table 2.8.A. Consumption of Coal for Electricity Generation by State, By Sector. https://www.eia.gov/electricity/monthly/epm_table_grapher.php?t=epmt_2_08_a

EPA. (n.d.). Carbon Monoxide's Impact on Indoor Air Quality. Retrieved March 10, 2020, from https://www.epa.gov/indoor-air-quality-iaq/carbon-monoxides-impact-indoorair-quality

EPA. (1989). Report to Congress on indoor air quality. https://www.epa.gov/reportenvironment/indoor-air-quality\#note2

EPA. (2018). Technical Support Document Estimating the Benefit per Ton of Reducing PM2.5 Precursors from 17 Sectors Background and Overview. 
https://www.epa.gov/sites/production/files/2018-

02/documents/sourceapportionmentbpttsd_2018.pdf

EPA. (2019a). Air Quality - National Summary.

EPA. (2019b). AVoided Emissions and geneRation Tool (AVERT): User Manual. Version 2.3 .

Federal Aviation Administration. (2011). Aviation Gasoline - Getting the Lead Out. https://www.faa.gov/about/initiatives/avgas/archive/2010-09-02/

Gillingham, K., Newell, R. G., \& Palmer, K. (2009). Energy Efficiency Economics and Policy. NW. www.rff.org

Goodkind, A. L., Tessum, C. W., Coggins, J. S., Hill, J. D., \& Marshall, J. D. (2019). Finescale damage estimates of particulate matter air pollution reveal opportunities for location-specific mitigation of emissions. Proceedings of the National Academy of Sciences of the United States of America, 116(18), 8775-8780. https://doi.org/10.1073/pnas.1816102116

Grennfelt, P., Engleryd, A., Forsius, M., Hov, Ø., Rodhe, H., \& Cowling, E. (2019). Acid rain and air pollution: 50 years of progress in environmental science and policy. In Ambio (Vol. 49, Issue 4, pp. 849-864). Springer Netherlands. https://doi.org/10.1007/s13280-019-01244-4

Grübler, A., Jefferson, M., \& Nakićenović, N. (1996). Global energy perspectives: A summary of the joint study by the international institute for applied systems analysis and world energy council. Technological Forecasting and Social Change, 51(3), 237264. https://doi.org/10.1016/0040-1625(95)00251-0

Ha, S., Zhu, Y., Liu, D., Sherman, S., \& Mendola, P. (2017). Ambient temperature and air quality in relation to small for gestational age and term low birthweight. Environmental Research, 155, 394-400. https://doi.org/10.1016/j.envres.2017.02.021 
Hayes, S., \& Kubes, C. (2018). Saving Energy, Saving Lives: The Health Impacts of Avoiding Power Plant Pollution with Energy Efficiency (Issue February).

Hogan, J. (1986). A Spirit Capable: The Story of Commonwealth Edison. The Mobium Press. https://archive.org/details/spiritcapablest00hoga

Höök, M., \& Aleklett, K. (2009). Historical trends in American coal production and a possible future outlook. International Journal of Coal Geology, 78(3), 201-216. https://doi.org/10.1016/j.coal.2009.03.002

Huang, Y. C. T., Rappold, A. G., Graff, D. W., Ghio, A. J., \& Devlin, R. B. (2012). Synergistic effects of exposure to concentrated ambient fine pollution particles and nitrogen dioxide in humans. Inhalation Toxicology, 24(12), 790-797. https://doi.org/10.3109/08958378.2012.718809

Illinois Coal Association. (n.d.). Illinois Coal Usage. http://www.illinoiscoal.org/illinoiscoal-usage 2

International Energy Agency. (2015). Energy Technology Perspectives 2015. International Energy Agency, 412. https://doi.org/10.1787/energy_tech-2015-en

Kravchenko, J., \& Lyerly, H. K. (2018). The Impact of Coal-Powered Electrical Plants and Coal Ash Impoundments on the Health of Residential Communities. North Carolina Medical Journal, 79(5), 289-300. https://doi.org/10.18043/ncm.79.5.289

Krewski, D., Jerrett, M., Burnett, R. T., Ma, R., Hughes, E., Shi, Y., Turner, M. C., Arden, C., Thurston, G., Calle, E. E., Thun, M. J., Beckerman, B., Deluca, P., Finkelstein, N., Ito, K., Moore, D. K., Newbold, K. B., Ramsay, T., Ross, Z., ... Tempalski, B. (2009). Extended Follow-Up and Spatial Analysis of the American Cancer Society Study Linking Particulate Air Pollution and Mortality Number 140 May 2009 PRESS VERSION. www.healtheffects.org

Levy, J. I., Spengler, J. D., Hlinka, D., Sullivan, D., \& Moon, D. (2002). Using CALPUFF 
to evaluate the impacts of power plant emissions in Illinois: Model sensitivity and implications. Atmospheric Environment, 36(6), 1063-1075. https://doi.org/10.1016/S1352-2310(01)00493-9

Levy, J. I., Woo, M. K., Penn, S. L., Omary, M., Tambouret, Y., Kim, C. S., \& Arunachalam, S. (2016). Carbon reductions and health co-benefits from US residential energy efficiency measures. Environmental Research Letters, 11(3). https://doi.org/10.1088/1748-9326/11/3/034017

Lippmann, M., Chen, L. C., Gordon, T., Ito, K., \& Thurston, G. D. (2013). National Particle Component Toxicity (NPACT) Initiative: integrated epidemiologic and toxicologic studies of the health effects of particulate matter components. Research Report $\begin{array}{llll}\text { (Health Effects } & \text { Institute), } & \text { 5-137, }\end{array}$ https://www.ncbi.nlm.nih.gov/pubmed/24377209

MacIntosh, D., \& Spengler, J. (2008). Emissions of hazardous air pollutants from coalfired power plants. In Environmental Health and Engineering Report (Vol. 17505).

Mudway, I. S., Krishna, M. T., Frew, A. J., MacLeod, D., Sandstrom, T., Holgate, S. T., \& Kelly, F. J. (1999). Compromised concentrations of ascorbate in fluid lining the respiratory tract in human subjects after exposure to ozone. Occupational and Environmental Medicine, 56(7), 473-481. https://doi.org/10.1136/oem.56.7.473

Muller, R. (Richard). (2013). Energy for future presidents: the science behind the headlines (1st ed.). W.W. Norton.

National Library of Medicine. (n.d.). Power Plants: Your Environment, Your Health. Retrieved February 26, 2020, from https://toxtown.nlm.nih.gov/sources-ofexposure/power-plants

O'Brien, B. (1997). The Effects of Title IV of the Clean Air Act Amendments of 1990 on Electric Utilities : An Update. 0582(March). 
Paul, G., Nolen, J. E., Alexander, L., Bender, L. K., Vleet, V., Barrett, W., Jump, Z., Rappaport, S., Samet, J. M., Ballentine, N., Nimirowski, T., Innocenzi, L., Wojs, V., Lavelle, L., Clark, C., Fitzgerald, J., Eyer, A., Lacina, K., Macmunn, A., ... Designs, O. (2019). Sota-2019-Full. https://www.lung.org/assets/documents/healthy-air/stateof-the-air/sota-2019-full.pdf

Phalen, R. F., \& Phalen, R. N. (2013). Introduction to Air Pollution Science. Jones \& Bartlett Learning. www.jblearning.com.

Platt, H. L. (1991). The electric city: energy and the growth of the Chicago area, 18801930 (First edit). The University of Chicago Press. https://www.amazon.com/Electric-City-Energy-Chicago-18801930/dp/0226670759/ref=sr_1_1 _keywords=9780226670751\&linkCode=qs\&qid=1 $585670590 \& s=$ books\&sr $=1-1$

RABL, A., \& SPADARO, J. V. (2006). Environmental Impacts and Costs of Energy. Annals of the New York Academy of Sciences, 1076(1), 516-526. https://doi.org/10.1196/annals.1371.059

Reidmiller, D. R., Avery, C. W., Easterling, D. R., \& Kunkel, K. E. (2018). USGCRP, 2018: Impacts, Risks, and Adaptation in the United States: Fourth National Climate Assessment, Volume II. chromeextension://onhiacboedfinnofagfgoaanfedhmfab/https://nca2018.globalchange.gov/d ownloads/NCA4_2018_FullReport.pdf

Reno, A. L., Brooks, E. G., \& Ameredes, B. T. (2015). Mechanisms of Heightened Airway Sensitivity and Responses to Inhaled SO2 in Asthmatics. In Environmental Health Insights (Vol. 9, Issue s1, p. 13). SAGE Publications Inc. https://doi.org/10.4137/EHI.S15671

Ross, K., Chmiel, J. F., \& Ferkol, T. (2012). The Impact of the Clean Air Act. Journal of Pediatrics, 161(5), 781-786. https://doi.org/10.1016/j.jpeds.2012.06.064 
Satterfield, Z. (2004). What does ppm or ppb mean? http://www.nesc.wvu.edu/ndwc/articles/ot/fa04/q\&a.pdf

Schmalensee, R., \& Stavins, R. N. (2019). Policy evolution under the Clean Air Act. Journal of Economic Perspectives, 33(4), 27-50. https://doi.org/10.1257/jep.33.4.27

Sheppard, D., Wong, W. S., Uehara, C. F., Nadel, J. A., \& Boushey, H. A. (1980). Lower threshold and greater bronchomotor responsiveness pf asthmatic subjects to sulfur dioxide. American Review of Respiratory Disease, 122(6), 873-878. https://doi.org/10.1164/arrd.1980.122.6.873

Sheppard, Dean. (1988). Sulfur dioxide and asthma-A double-edged sword? Journal of Allergy and Clinical Immunology, 82(6), 961-964. https://www.sciencedirect.com/science/article/abs/pii/0091674988901315?via\%3Di hub

Stevenson, E., Engle, H., Engle, H., Stoddard, G. D., Ph, D., \& Litt, D. (n.d.). DEPARTMENT OF REGISTRATION AND EDUCATION White Crappie in Illinois.

U.S. Census Bureau. (n.d.). Census Regions and Divisions of the United States. Retrieved April 21, 2020, from https://www2.census.gov/geo/pdfs/mapsdata/maps/reference/us_regdiv.pdf

U.S. Department of Energy. (2008). Energy Efficiency Trends in Residential and Commercial Buildings (Issue October).

U.S. Department of Energy. (2018). Status of State Energy Code Adoption | Building Energy Codes Program. https://www.energycodes.gov/adoption/states

U.S. Environmental Protection Agency (EPA). (2016). The National Ambient Air Quality Standards for Particle Pollution: REVISED AIR QUALITY STANDARDS FOR PARTICLE POLLUTION AND UPDATES TO THE AIR QUALITY INDEX (AQI).

United States Environmental Protection Agency. (n.d.). Basic Information about Lead Air 
Pollution | Lead (Pb) Air Pollution | US EPA. Retrieved March 10, 2020, from https://www.epa.gov/lead-air-pollution/basic-information-about-lead-airpollution\#how

WHO. (2007). Global surveillance, prevention and control of Chronic Respiratory Diseases: A comprehensive approach.

Wilson, A., Patterson, J., Wasserman, K., \& Fink, K. (n.d.). Coal Blooded Putting Profits Before People.

Wuebbles, D. J., Fahey, D. W., Hibbard, K. A., Dokken, D. J., Stewart, B. C., \& Maycock, T. K. (2017). Climate science special report: fourth National Climate Assessment. U.S. Global Change Research Program, 1, 470. https://doi.org/10.7930/J0J964J6 


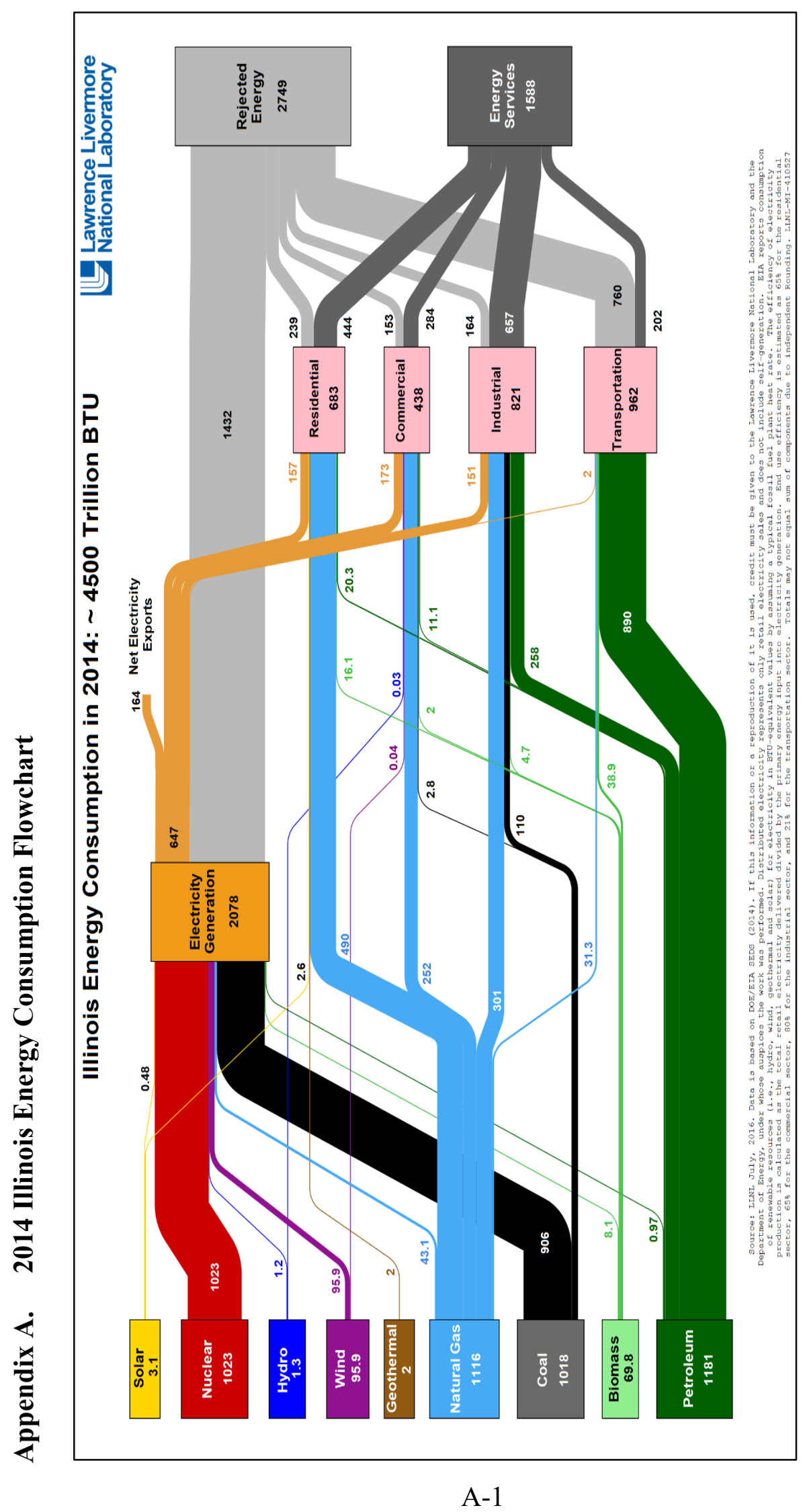




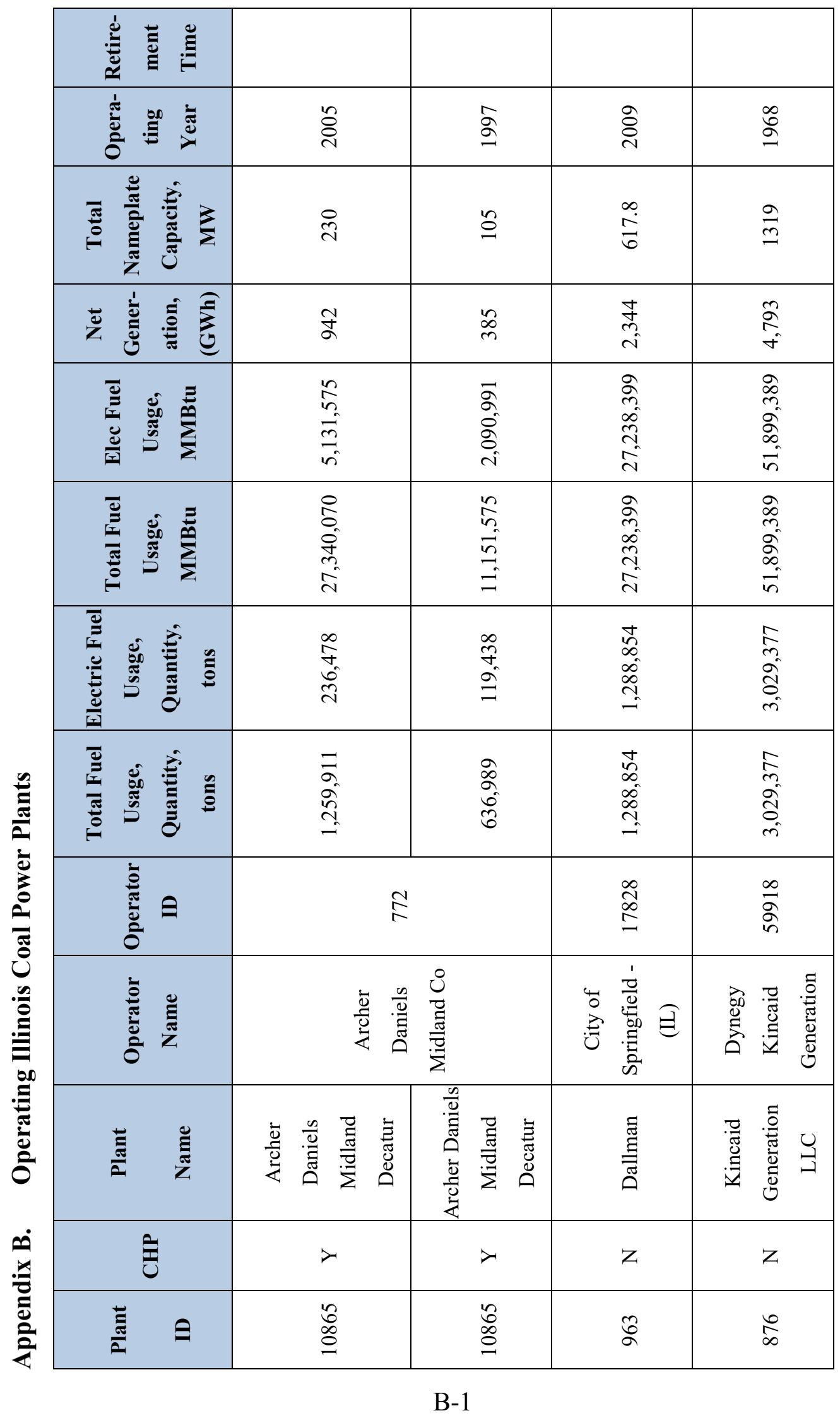




\begin{tabular}{|c|c|c|c|c|c|}
\hline 竧 言总 & & ฐ & ฐ & & ฐ \\
\hline 妾高 & $\stackrel{\Re}{\Xi}$ & $\stackrel{\infty}{\stackrel{\infty}{\sigma}}$ & $\stackrel{\text { gे }}{a}$ & 茖 & $\stackrel{\tilde{a}}{\Phi}$ \\
\hline 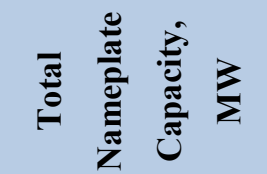 & 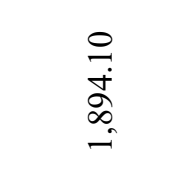 & $\underset{\stackrel{\infty}{\infty}}{\stackrel{\infty}{q}}$ & 家 & 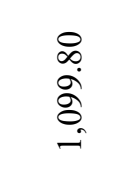 & 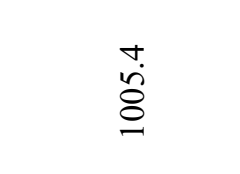 \\
\hline 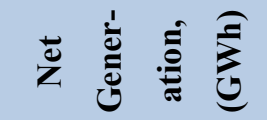 & స్고 & 寿 & $\stackrel{\bar{N}}{=}$ & 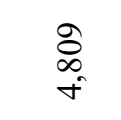 & ने \\
\hline 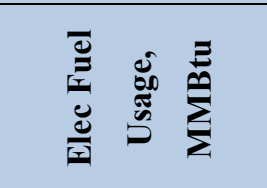 & 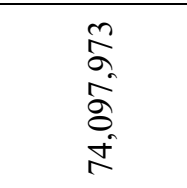 & 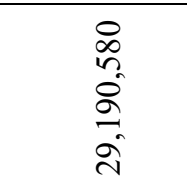 & 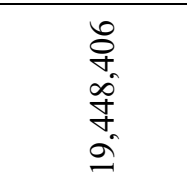 & $\begin{array}{c}0 \\
0 \\
0 \\
0 \\
0 \\
0\end{array}$ & 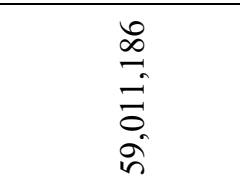 \\
\hline 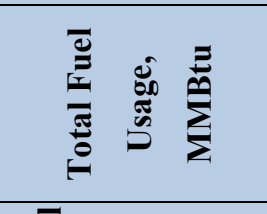 & 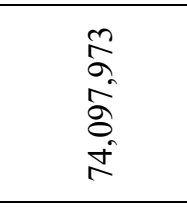 & 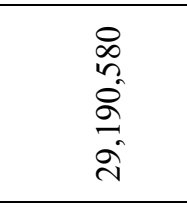 & 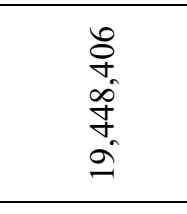 & 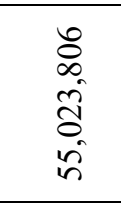 & 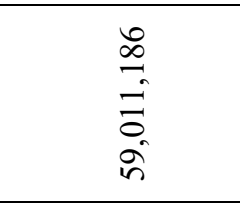 \\
\hline 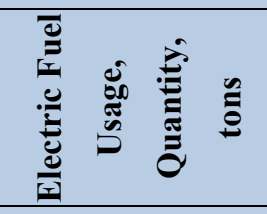 & $\begin{array}{l}\text { वे } \\
\text { iv } \\
\text { वे } \\
\text { वे }\end{array}$ & 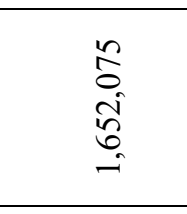 & $\begin{array}{l}\stackrel{0}{0} \\
\text { o. } \\
\stackrel{0}{=}\end{array}$ & $\begin{array}{l}5 \\
\text { s. } \\
\text { ले } \\
\text { mेt }\end{array}$ & 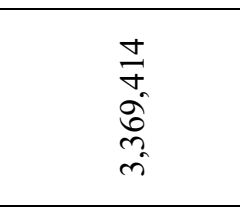 \\
\hline 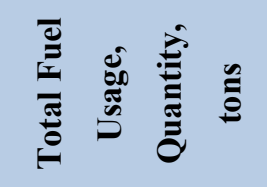 & 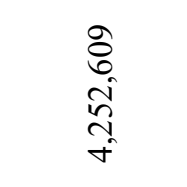 & 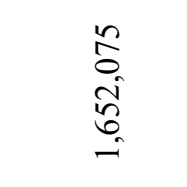 & 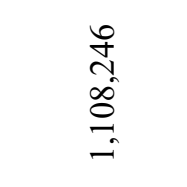 & $\begin{array}{l}\text { 总 } \\
\text { ले } \\
\text { ले }\end{array}$ & 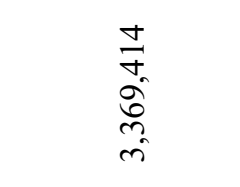 \\
\hline 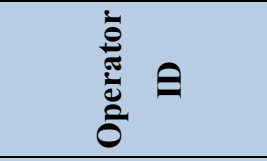 & \multicolumn{3}{|c|}{ 空 } & $\underset{\substack{\infty \\
i n}}{i n}$ & 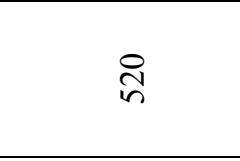 \\
\hline 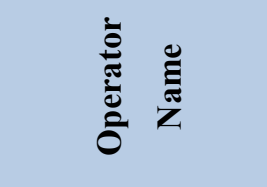 & \multicolumn{3}{|c|}{ 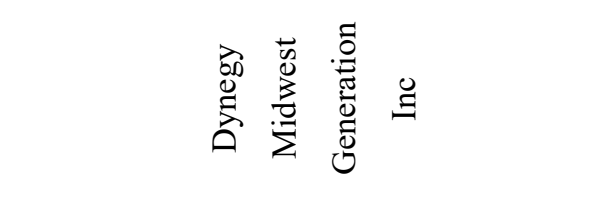 } & 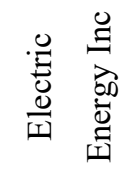 & 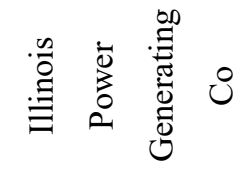 \\
\hline 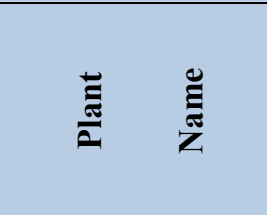 & 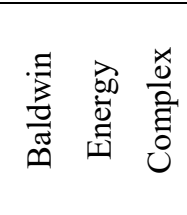 & 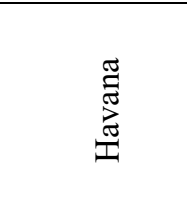 & 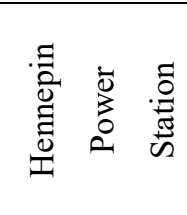 & 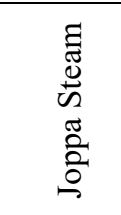 & 密 \\
\hline $\bar{E}$ & z & z & z & z & z \\
\hline 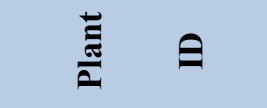 & $\stackrel{\infty}{\infty}$ & $\bar{\infty}$ & జ & $\infty$ & $\vec{\Phi}$ \\
\hline
\end{tabular}

B-2 


\begin{tabular}{|c|c|c|c|c|c|c|c|}
\hline$\stackrel{d}{\stackrel{\Xi}{\Xi}} \stackrel{\Xi}{\Xi}$ & & & & ஓे & & & \\
\hline 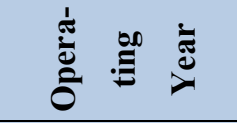 & $\hat{ล}$ & $\stackrel{N}{\Omega}$ & & $\stackrel{0}{\stackrel{2}{a}}$ & $\overline{\check{\sigma}}$ & & $\stackrel{n}{a}$ \\
\hline 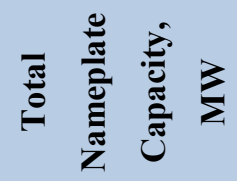 & $\frac{7}{\sqrt{0}}$ & $\stackrel{\Re}{\dot{f}}$ & & $\vec{f}$ & $\begin{array}{l}0 \\
\dot{H}\end{array}$ & & $\begin{array}{l}0 \\
\dot{\infty} \\
\infty \\
\end{array}$ \\
\hline そ & $\begin{array}{l}\bar{\sim} \\
m\end{array}$ & $\begin{array}{l}\infty \\
\infty \\
i \\
m\end{array}$ & & 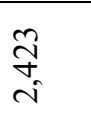 & $\stackrel{m}{\sim}$ & & $\begin{array}{l}\hat{8} \\
i n \\
\forall\end{array}$ \\
\hline 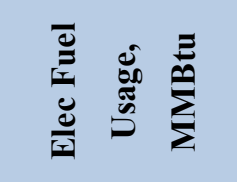 & 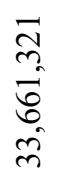 & $\begin{array}{l}\infty \\
\infty \\
n \\
a \\
a \\
\dot{m}\end{array}$ & & $\begin{array}{l}\infty \\
\infty \\
\tilde{n} \\
\bar{\sigma} \\
\hat{n}\end{array}$ & 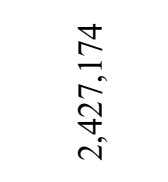 & & $\begin{array}{l}\text { ते } \\
\text { ñ } \\
\text { ñ }\end{array}$ \\
\hline 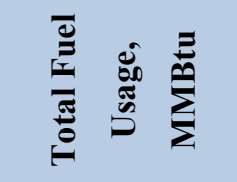 & $\begin{array}{l}\vec{a} \\
\text { ñ } \\
\overrightarrow{0} \\
\stackrel{0}{n} \\
\tilde{m}\end{array}$ & $\begin{array}{l}\infty \\
\infty \\
2 \\
a \\
\dot{m}\end{array}$ & & $\begin{array}{l}\bar{\infty} \\
\infty \\
\tilde{a} \\
\tilde{a}\end{array}$ & 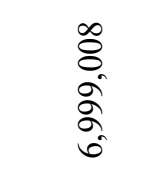 & & $\begin{array}{l}\hat{\tilde{n}} \\
\hat{n} \\
\frac{\hat{n}}{n}\end{array}$ \\
\hline 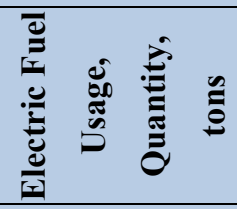 & $\begin{array}{l}\stackrel{a}{d} \\
i \\
a \\
\end{array}$ & 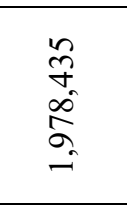 & & 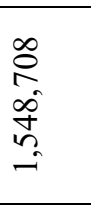 & 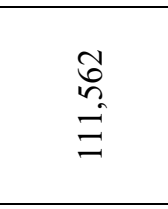 & & $\begin{array}{l}\stackrel{\mathscr{N}}{m} \\
\stackrel{m}{ \pm}\end{array}$ \\
\hline 兽 & 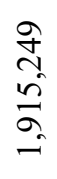 & $\begin{array}{l}\tilde{n} \\
\stackrel{f}{0} \\
\infty \\
\hat{\sigma} \\
-\end{array}$ & & $\begin{array}{l}\infty \\
\stackrel{\infty}{2} \\
\infty \\
i \\
\\
-\end{array}$ & $\begin{array}{l}\overrightarrow{0} \\
\stackrel{0}{\pi} \\
\stackrel{n}{n}\end{array}$ & & $\begin{array}{l}\stackrel{\mathscr{N}}{N} \\
\stackrel{m}{\dot{m}}\end{array}$ \\
\hline 㐫 & & & $\begin{array}{l}\stackrel{\circ}{n} \\
\frac{n}{\sigma}\end{array}$ & & $\underset{\text { สิ }}{\text { ป }}$ & & $\begin{array}{l}+ \\
\stackrel{\infty}{\beth}\end{array}$ \\
\hline 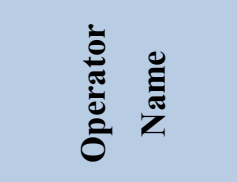 & & 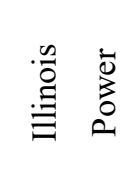 & 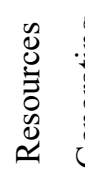 & كَ & 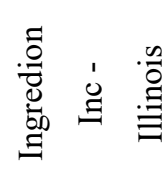 & 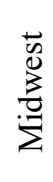 & 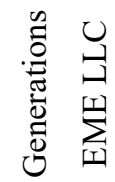 \\
\hline 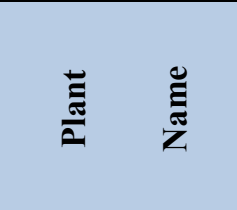 & $\begin{array}{l}\overline{0} \\
\sum_{0}^{2} \\
\text { Z }\end{array}$ & 品竞 & & 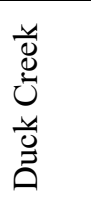 & 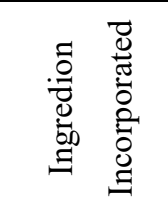 & & $\begin{array}{l}5 \\
0 \\
000 \\
0 \\
0 \\
0\end{array}$ \\
\hline$\hat{\bar{U}}$ & $\mathrm{z}$ & $\mathrm{z}$ & & $\mathrm{z}$ & $\lambda$ & & $\mathrm{z}$ \\
\hline$\stackrel{\vec{E}}{a} \quad$ & $\frac{1}{8}$ & $\begin{array}{l}\infty \\
\infty \\
\infty\end{array}$ & & $\stackrel{0}{8}$ & $\begin{array}{l}0 \\
i n \\
i n \\
i n\end{array}$ & & $\underset{\infty}{\infty}$ \\
\hline
\end{tabular}

B-3 


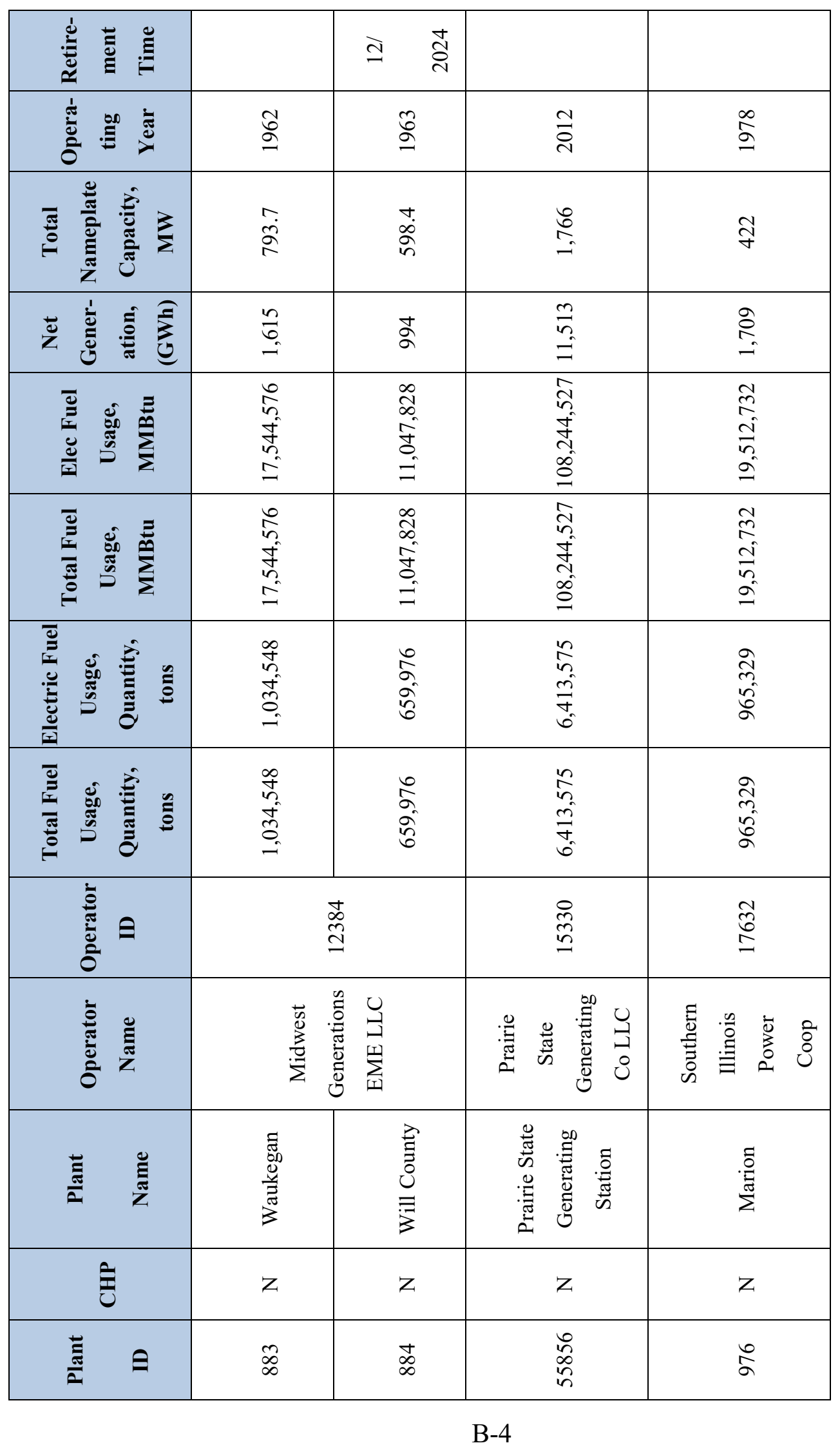




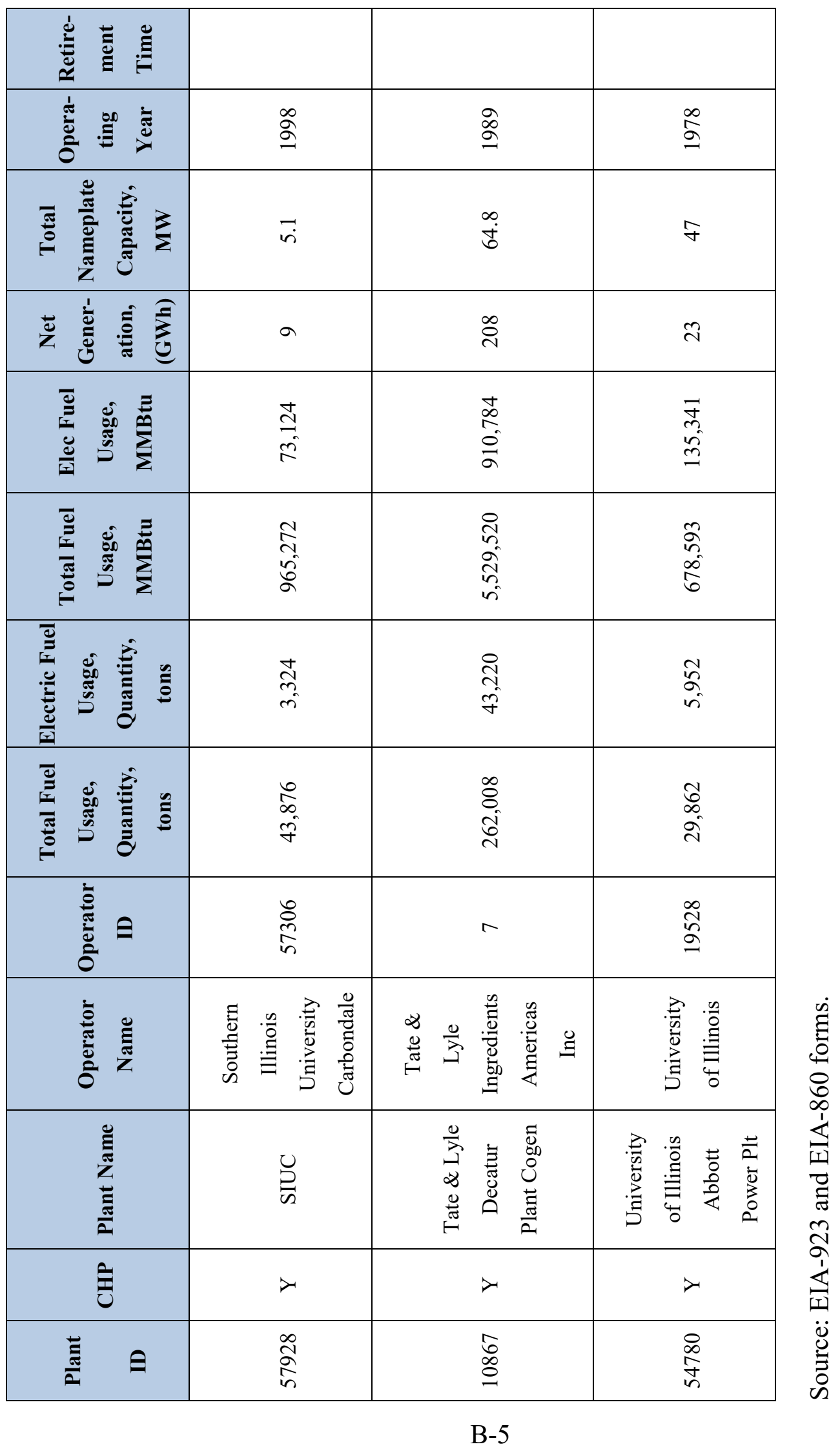




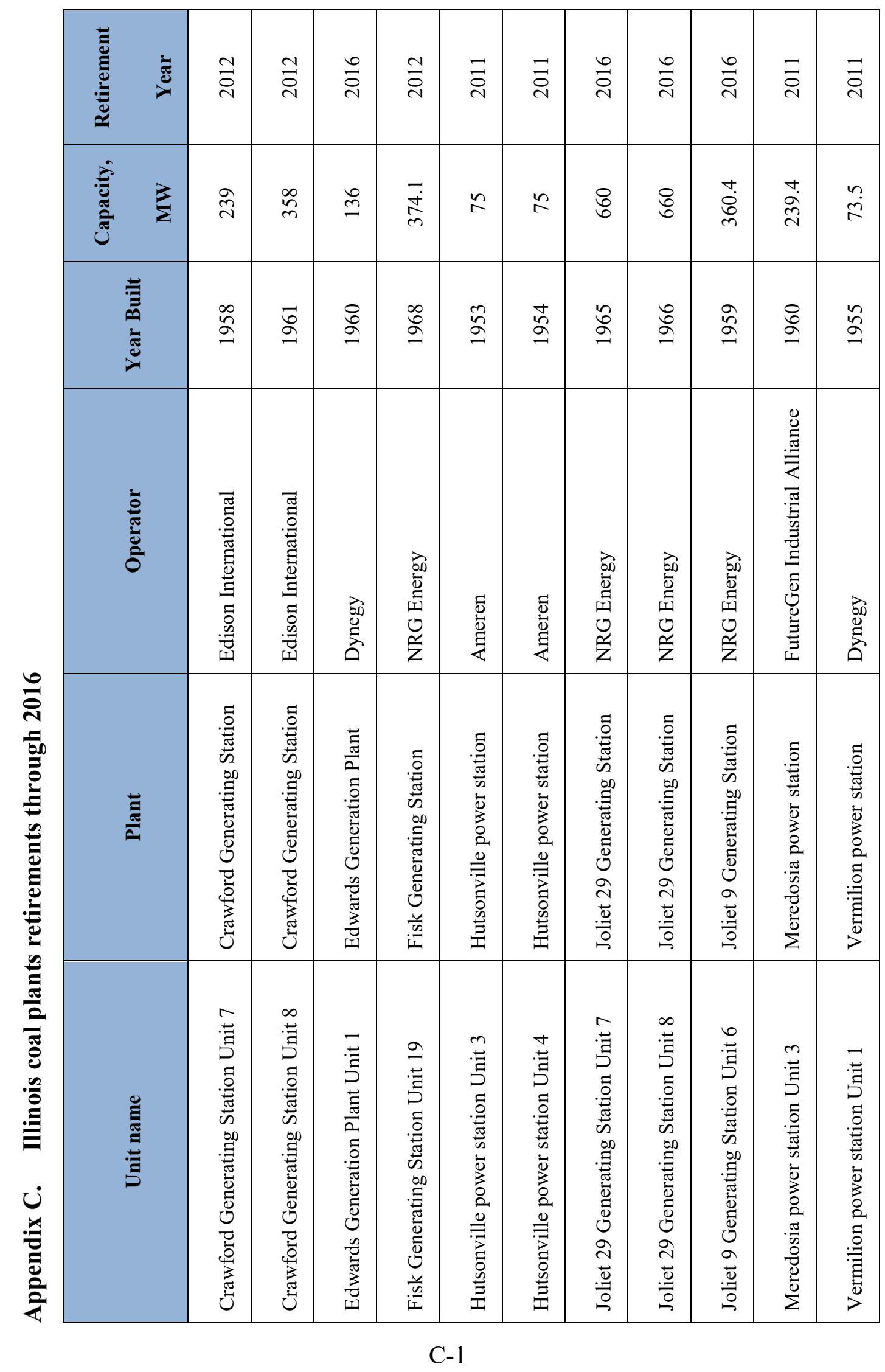




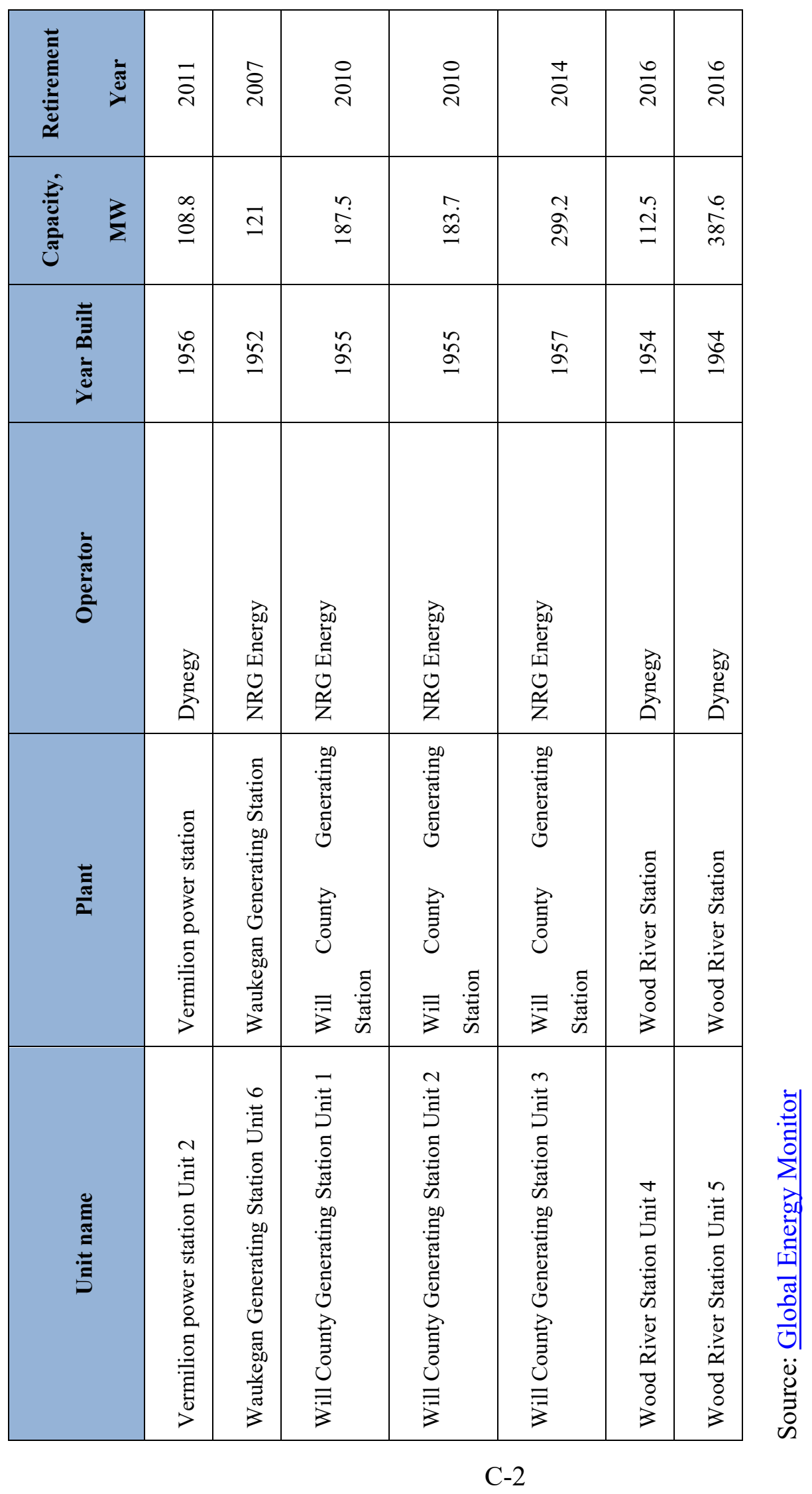




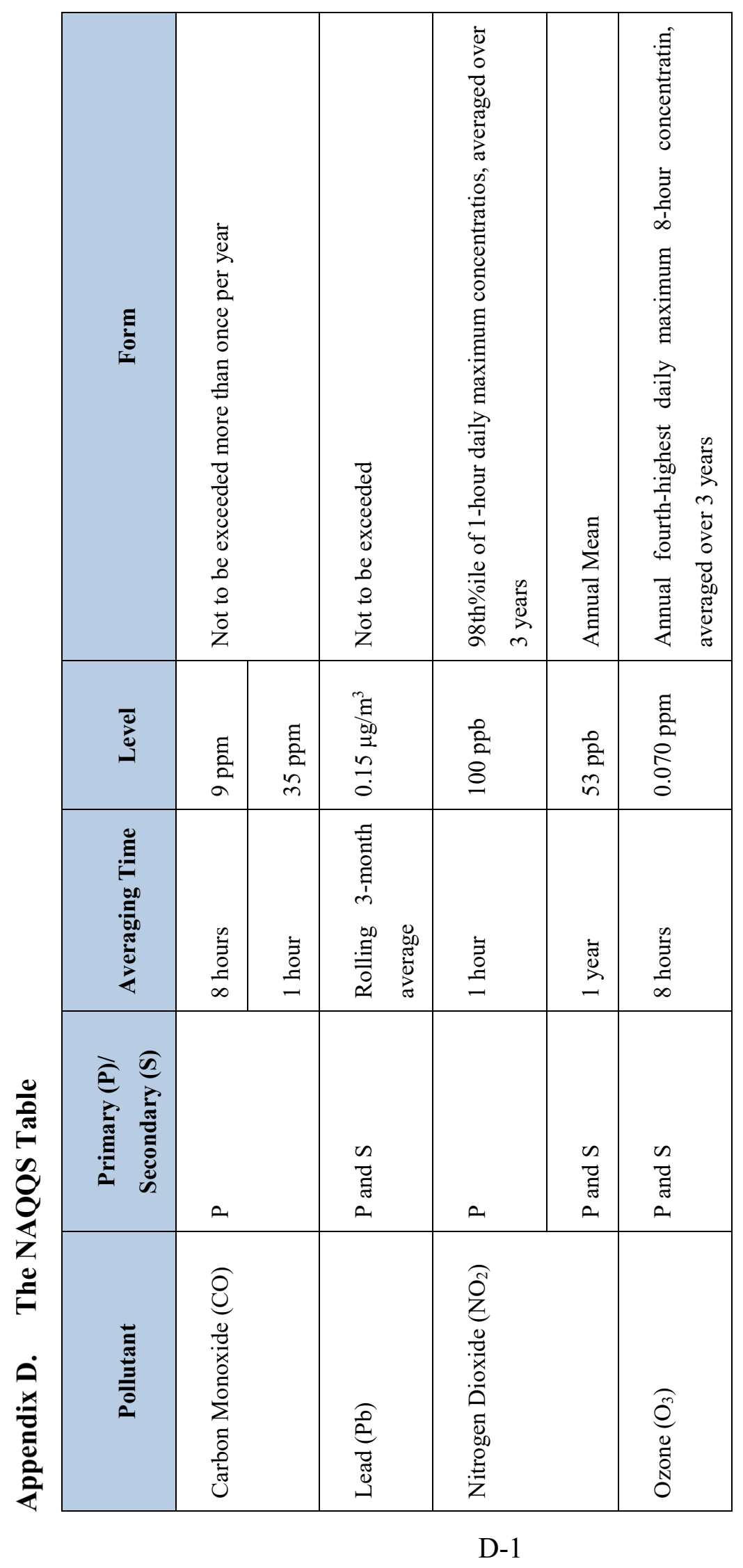




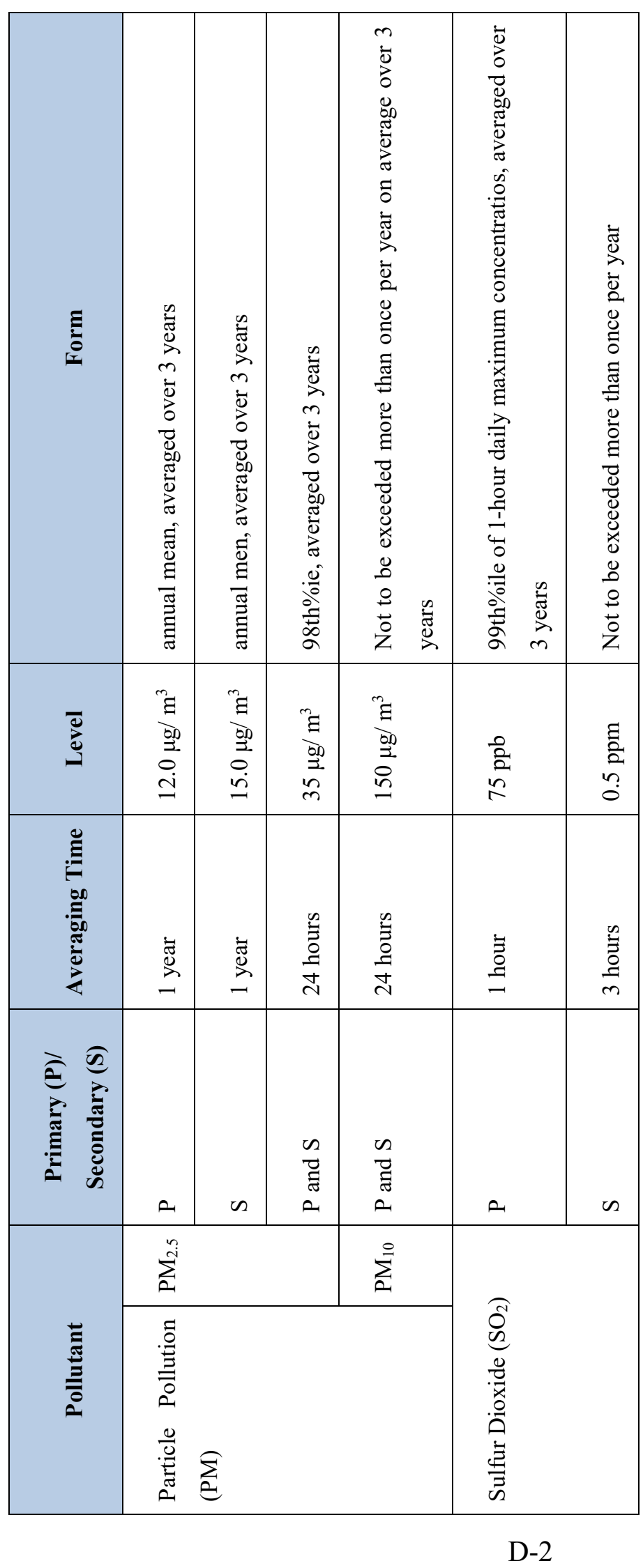




\section{Appendix E. Copyright documentation}

Figure 4.2: "Comparative particle sizes" by Environmental Protection Agency (EPA). Downloaded from https://www.epa.gov/pm-pollution/particulate-matter-pm-basics. Accessed February 2020

Figure 4.3: "The ground ozone formation process" by EPA. Downloaded from https://www.epa.gov/ground-level-ozone-pollution/ground-level-ozone-basics\#effects.

Assessed February 2020

Figure 4.5: "Number of days reaching unhealthy levels for sensitive groups and above for the Chicago Metropolitan Area” by EPA “A Look Back: Ozone and PM in 2018". Downloaded from https://epa.maps.arcgis.com/apps/Cascade/index.html?appid=bd0b760468a54c7e807ddf7 29f03bca4. Assessed February 2020

Figure 7.2: "Map of AVERT regions" by EPA "AVERT Tutorial: Getting Started Identify Your AVERT Region(s). Downloaded from https://www.epa.gov/statelocalenergy/avert-tutorial-getting-started-identify-your-avertregions. Assessed March 2020

Figure 7.4: "Hypothetical dispatch curve for summer 2011" by the U.S. Energy Information Administration (EIA). "Electric generator dispatch depends on system demand and the relative cost of operation". Downloaded from https://www.eia.gov/todayinenergy/detail.php?id=7590. Assessed March 2020

Appendix A: "2014 Illinois Energy Consumption Flowchart" by the Lawrence Livemore National Laboratory. Downloaded from https://flowcharts.llnl.gov/commodities/energy. Assessed January 2020 